\title{
Polymer nanocomposites: Why their mechanical performance does not justify the expectation and a possible solution to the problem?
}

\author{
S. Fakirov*
}

The University of Auckland, Department of Mechanical Engineering, 314 Khyber Pass Road, Newmarket, 1142 Auckland, New Zealand

Received 25 September 2019; accepted in revised form 18 December 2019

\begin{abstract}
The expected order-of-magnitude enhancement in modulus (at loadings less than 1\%) of polymer nanocomposites has proven elusive - the observed improvements are 10-35\% only. The failure of the concept has been attributed to poor dispersion, poor interfacial load transfer, process-related deficiencies, and others.

Due to the inherent property of the nano-size materials, their extremely high specific surface, they tend to agglomerate, and their further dispersion in the matrix component is practically impossible. For this reason, the composites prepared via blending a polymer with a nano-size material are microcomposites instead of nanocomposites, as demonstrated by light scattering studies. So long as reliable tools and/or techniques for proper dispersion of nanomaterials are missing, we must use methods free of the dispersion step in the manufacturing process.

The relatively new 'concept of converting instead of adding' offers two such techniques - instead to take the matrix and the reinforcement in their final form and blend them, one takes one component only and during the processing creates the missing second component. Both approaches result in true nanocomposites with superior mechanical performance - the improvements of the tensile strength for nanofibrillar polymer-polymer and single polymer composites are up to 200 and $440 \%$, respectively, (or even up to $650 \%$ if trans-reaction catalyst is used).
\end{abstract}

Keywords: polymer nanocomposites, mechanical performance, dispersion problem, concept 'converting instead of adding', nanofibrillar polymer-polymer composites

\section{Introduction}

Nanomaterials are generally considered as a discovery of modern science. In fact, they have a very long history - nanoparticles have been used by artisans as far back as the ninth century in Mesopotamia for generating a glittering effect on the surface of pots. The peculiarities of nanomaterials arise mainly from their sizes, which are usually defined as smaller than onetenth of a micrometer in at least one dimension [1]. In 2011 the European Commission adopted the following definition of a nanomaterial: '... 50\% or more of the particles in the number size distribution, one or more external dimensions is in the size range $1-100 \mathrm{~nm} \ldots{ }^{\prime}[2]$.

A common characteristic feature of all nano-sized materials, regardless of their chemical composition and method of manufacturing, is the extremely increased ratio of surface area to volume. For example, $1 \mathrm{~kg}$ of particles of $1 \mathrm{~mm}^{3}$ has the same surface area as $1 \mathrm{mg}$ of particles of $1 \mathrm{~nm}^{3}$. The natural tendency to reduce this free surface is the driving force for agglomeration of nanoparticles in larger formations. Discovery with a revolutionary effect in the nanoscience was that of Iijima [3] who prepared carbon 
nanotubes (CNTs). It turned out that this all-carbon material is the most ideal material ever created - it has the highest heat conductivity, highest electrical conductivity, the highest mechanical properties, etc. and thus attracted the attention of researchers from various fields, including polymer science and technology. For example, with tensile moduli in the terapascal range and lengths exceeding $10 \mu \mathrm{m}$ of carbon nanotubes, simple composite models predict order-of-magnitude enhancement in modulus at loadings less than $1 \%$. For this reason, a couple of decades ago, it was believed that the most common polymer composites comprising about $30 \%$ glass fibers will be replaced by the nanocomposites having only $2-5 \%$ nano-sized filler as reinforcement! Unfortunately, this expectation turned out to be elusive.

\section{The reality regarding the mechanical performance of polymer nanocomposites}

As mentioned above, such systems have attracted enormous interest from the materials community because they theoretically promise a substantial improvement of mechanical properties at very low filler loadings. Besides, polymer nanocomposites are compatible with conventional polymer processing, thus avoiding costly layup required for the fabrication of conventional fiber-reinforced composites.

'Introductory paragraphs similar to the above can be found in hundreds of nanocomposite papers. With the exception of reinforced elastomers, nanocomposites have not lived up to expectations. Although claims of modulus enhancement by factors of 10 exist, these claims are offset by measurements that show little or no improvement... The lacklustre performance of nanocomposites has been attributed to a number of factors including poor dispersion, poor interfacial load transfer, process-related deficiencies, and others' [4].

Discussing the mechanical behavior of polymer nanocomposites it should be stressed that an improvement of $20 \%$ (for tensile strength) and $50 \%$ (for the modulus of elasticity) is quite typical for all polymer nanocomposites [5]. According to Bousmina [6], only in exceptional circumstances can one observe an improvement greater than $30 \%$ in the mechanical performance of nanocomposites. More specifically, Zhang et al. [7] studied thoroughly the case of polypropylene (PP)/ $/ \mathrm{SiO}_{2}$ nanocomposites in which the nanoparticles have been coated by various polymers to improve the interfacial adhesion. They reported mechanical properties (Young's modulus and tensile strength) only $20-25 \%$ higher than those of the neat PP [7].

The above conclusions were supported by the statements of Schaefer and Justice in their review 'How Nano Are Nanocomposites?' [4]: 'Composite materials loaded with nanometer-sized reinforcing fillers are widely believed to have the potential to push polymer mechanical properties to extreme values. Realization of anticipated properties, however, has proven elusive'.

Finally, let me mention in this respect the statement in a recent review on the practical applicability of polymer nanocomposites [8]: 'Initial developments of nanocomposite thermosets focused on high aspect ratio nanoparticles such as nanoclays, carbon nanotubes and more recently graphene. Generally, these systems showed 10-35\% improvement in mechanical properties with 0.2-5 wt\% filler. However, the translation of these improvements to prepregs or laminates proved to be difficult due to processing issues, including extremely high viscosity, nanoparticle filtration, nanoparticles agglomeration, and void formation.'

It seems rather realistic to assume that polymer nanocomposites prepared via melt blending of the two basic components, the matrix, and the reinforcement, are characterized by a maximum improvement of their mechanical properties by $30-35 \%$ as compared with the respective neat isotropic matrix. Such a result is quite far from the expected 10-fold (at least!) improvement.

An interesting question regarding the reasons for this drastic discrepancy arises.

The concept of polymer nanocomposites, that is, the expectation that using $1-5 \mathrm{wt} \%$ of nanofiller instead of the common $30-40 \mathrm{wt} \%$, it will be possible to realize improvements of an order of magnitude as compared with the traditional composites materials as well as to enhance the environmental impact of these materials failed for the following reasons [4]:

(i) Poor dispersion

(ii) Poor interfacial load transfer

(iii) Process-related deficiencies

(iv) Poor alignment

(v) Poor load transfer to the interior of filler bundles (vi) The fractal nature of filler clusters.

Nowadays, a rather large number of nano-sized materials are available, and nevertheless, the preparation 
of true nanocomposites is not an easy task. The basic problem in the manufacturing of polymer nanocomposites is the dispersion in the matrix material of the reinforcing component to single nanoparticles. Due to the inherent property of the nano-sized materials, namely, the extremely high specific surface, they tend to agglomerate and their further dispersion in the matrix component is practically impossible. In this respect, it seems useful to cite here the opinion of Greiner and Wendorff [9] expressed in their excellent review on electrospinning as a method for the preparation of ultrathin fibers and their application as reinforcing material for nanocomposites. After listing the advantages of the electrospun nanofibers as reinforcement over macroscopic fibers as owing to their extremely high aspect ratio, little refraction of light (due to the small diameters) resulting in transparent reinforced matrices, the authors [9] conclude: 'Given the advantages of nanofibers for reinforcement, the number of investigations on this topic is rather small. The main problems, to which there is no convincing solution, yet, are the dispersion of the electrospun nanofiber webs and the control of the nanofiber orientation in the polymer matrix.

The felt-mat structure of the nonwoven is, for the most part, maintained upon the incorporation of the nanofibers into the matrix. Attempts to disperse single nanofibers from the nonwoven mats using ultrasound, kneaders, or high-speed stirrers have only been marginally successful. Very similar problems occurred in matrix reinforcement with carbon nanotubes and nanofilaments [10]' [9].

Obviously, in addition to the attempts for solving of the above-formulated problems, new routes to the same target - the creation of polymer nanocomposites - must be researched. The main targets of this review article are two. The first one is to collect enough proof from the literature demonstrating that polymer composites prepared via blending the matrix and the nanomaterials are not NANO- but MICROcomposites due to the non-proper dispersion (to single nanoparticles!). For this purpose, only results of scattering techniques being relevant for this task must be used and not electron microscopic observations being an inappropriate technique for this purpose. The second task is to offer an example of how one could avoid the difficult step of reinforcement dispersion. This can be achieved via the application of the new converting instead of adding concept, i.e. converting the bulk polymer into nano-size material instead of blending the polymer with nanofillers. In this way, avoiding the practically non-soluble problem of proper dispersion the SEM observations demonstrate that in the nano-fibrillar polymer-polymer and single polymer composites, the reinforcing nanofibrils (with diameters between 50 and $250 \mathrm{~nm}$ !) are dispersed to single nanoparticles - no aggregates of them are observed.

As a matter of fact, the single polymer and polymerpolymer composites are favoured since they offer the opportunity for demonstration of how we can solve the currently non-soluble problem regarding the proper dispersion of the reinforcing nanomaterials in the polymer matrix. It is to be stressed that the suggested approach for avoiding the dispersion step in the preparation of polymer nanocomposites is currently applicable to single polymer and polymer-polymer composites only.

\section{Do polymer nanocomposites prepared via blending a polymer with nanomaterial really exist?}

Such question sounds rather provocative but if we remember the criteria according to which composite materials are categorized, we will see that the question is quite reasonable [11]. Depending on the sizes of the reinforcing filler we distinguish between macrocomposites (the common ones), microcomposites when the sizes are in the micrometer range and nanocomposites if the single reinforcing particles are nano-size particles, i.e. with dimensions below $100 \mathrm{~nm}$ or around this size.

Dealing with this 'terminological' issue, it seems important to be reminded how polymer nanocomposites are prepared [12]. The most common practice is to blend a polymer (the matrix) with nano-size material (reinforcement) and to use as the title of paper the modern word 'nanocomposite.' In rare cases, attempts are undertaken to determine the degree of dispersion and if this is done, it is by using electron microscopy. Usually, 2-3 micrographs are incorporated demonstrating a couple of nano-size particles, which show how these particles look. At the same time, these photographs offer no information about their amount in the sample. The question regarding the degree of dispersion is not addressed. Such information can be obtained by using scattering techniques - X-ray, neutron scattering, etc. This important detail is also stressed in the recent review on the practical applicability of polymer nanocomposites [8]. 
It should be added that electron microscopy also reveals rather large aggregates of nanoparticles with sizes closer to the micrometer range rather than to the nanometre size. Their existence is to be expected considering the extremely strong tendency of nanosize materials to reduce the surface energy via agglomeration. Due to the nanoscale structure and Van der Waals forces, nanoparticles have shown a great tendency to self-aggregation, self-agglomeration and self-assembly making their dispersion into the polymer matrices very difficult. In contrast, nanoscale dispersion is a critical requirement to take the full advantage of nanoparticles in polymer nanocomposites [13-16]. The question is if these aggregates dominate in the sample. The answer can be found if we return to the scattering techniques, for example, light scattering.

There are polymers that are completely transparent, i.e. they let the light trough on $100 \%$ as, for example, atactic poly(methyl methacrylate) (at-PMMA), atactic polystyrene (at-PS) and, to some extent, polycarbonates (PC) and polyarylates (PAr). They can be used as a matrix for preparation of transparent nanocomposites via blending with nano-size fillers.

The nanomaterials of inorganic origin have typical sizes below $100 \mathrm{~nm}$ and, in many cases around 2$5 \mathrm{~nm}$. If the dispersion during mixing with the matrix is good, i.e., up to single nanoparticles, the transparency should not be different from that of the matrix, that is, the transmission of the light must be $100 \%$. This situation is due to the known fact that light scattering can be observed only if particles have sizes in the range of the size of the wavelength of the used light, which for the common light is $500-600 \mathrm{~nm}$.

Let look at the results of such studies summarized in Table 1. For example, nanocomposites have been manufactured from completely transparent at-PMMA ( $100 \%$ transmission of the light) and nano-size $\mathrm{ZnO}$ (particles of $75 \mathrm{~nm}$ in concentration $1 \mathrm{wt} \%$ ). The used light was with wavelength $\lambda=600 \mathrm{~nm}$. The measured amount of transmitted light is only $2 \%$ but it increases up to $50 \%$ if the concentration of the filler drops to $0.01 \%$ (Sample \# 2, Table 1).

It should be mentioned that in all cited cases (Table 1) the thickness of the samples subjected to light transmission measurement has been between 1 and $4 \mathrm{~mm}$. From the data presented in Table 1 one can conclude that: (i) the polymers used as matrix are inherently completely transparent materials, (ii) the reinforcing nanomaterials used have dimensions below $100 \mathrm{~nm}$ (typically a couple of $\mathrm{nm}$ for the majority of cases), and (iii) for the light transmission measurement a light with a wavelength between 500 and $600 \mathrm{~nm}$ has been used. If the studied composites are really polymer

Table 1. Examples of light transmission of polymer nanocomposites where the matrix is inherently transparent material (light transmission of $100 \%$ ) (Adapted from Fakirov S.: Nanofibrillar polymer-polymer and single polymer composites via the 'converting instead of adding' concept - examples of true polymer nanocomposite. Advanced Industrial and Engineering Polymer Research, 1, 40-47 (2018), [11]).

\begin{tabular}{|c|c|c|c|c|c|}
\hline$\#$ & Transmission of light & Specimen thickness & Filling degree & Filler size & Ref. \\
\hline \multicolumn{6}{|c|}{ Matrix of at-PMMA } \\
\hline 1. & $95 \%(600 \mathrm{~nm}, 20 \mathrm{wt} \%)$ & Thin & $0-20 \mathrm{wt} \%$ & $\mathrm{ZrO}_{2} / \mathrm{SiO}_{2}(<100 \mathrm{~nm})$ & {$[17]$} \\
\hline \multirow[t]{3}{*}{2.} & $2 \%(1 \mathrm{wt} \%, 600 \mathrm{~nm})$ & $3.5 \mathrm{~mm}$ & up to $1 \mathrm{wt} \%$ & $\mathrm{ZnO}(75 \mathrm{~nm})$ & {$[18]$} \\
\hline & $50 \%(0.01 \mathrm{wt} \%)$ & & $0.01 \mathrm{wt} \%$ & & \\
\hline & $<90 \%$ (0.01 wt\%, prepolymer) & & $0.01 \mathrm{wt} \%$ & & \\
\hline 3. & $80 \%(600 \mathrm{~nm}, 15 \mathrm{wt} \%)$ & - & $0-15 \mathrm{wt} \%$ & $\mathrm{ZrO}_{2}(4 \mathrm{~nm})$ & {$[19]$} \\
\hline 4. & $90 \%(600 \mathrm{~nm})$ & $4 \mathrm{~mm}$ & $0.5 \mathrm{wt} \%$ & $\mathrm{ZnO}(2.3 \mathrm{~nm})$ & {$[20]$} \\
\hline 5. & $>85 \%$, above $400 \mathrm{~nm}$ & $0.127 \mathrm{~mm}$ & $0.26 \mathrm{wt} \%$ & SWNT & {$[21]$} \\
\hline 6. & Increased absorb. $>600 \mathrm{~nm}-$ & $100-300 \mu \mathrm{m}$ & - & $\mathrm{Fe}_{2} \mathrm{O}_{3}(8-200 \mathrm{~nm})$ & {$[22]$} \\
\hline \multicolumn{6}{|c|}{ Matrix of at-PS } \\
\hline 7. & Good, brown coloured, $550 \mathrm{~nm}$ & $1 \mathrm{~mm}$ & $3-15 \mathrm{wt} \%$ & $\mathrm{Fe}_{3} \mathrm{O} 410 \times 50 \mathrm{~nm}$ & {$[23]$} \\
\hline 8. & 'Quite' transparent, >550 nm & $100 \mu \mathrm{m}$ & $5-15 \mathrm{wt} \%$ & $\mathrm{Fe}_{3} \mathrm{O} 410 \times 50 \mathrm{~nm}$ & {$[24]$} \\
\hline 9. & Decreases to $75 \%(20 \mathrm{wt} \%)$ & $2.5 \mu \mathrm{m}$ & up to $95 \mathrm{wt} \%$ & $\mathrm{CeO}(20 \mathrm{~nm})$ & {$[24]$} \\
\hline 10. & High & $20 \mathrm{~nm}$ (LED) & $\mathrm{Zn}: 8.2, \mathrm{Cu}: 0.12 \mathrm{wt} \%$ & $\mathrm{ZnS}: \mathrm{Cu}(3 \mathrm{~nm})$ & {$[25]$} \\
\hline \multicolumn{6}{|c|}{ Matrix of other transparent polymers (PC, PAr) } \\
\hline 11. & $80 \%(2 \mathrm{wt} \%, 600 \mathrm{~nm})$ & $0.15 \mathrm{~mm}$ & $2 \mathrm{wt} \%$ & $\mathrm{AlO}_{2}$ (whisker) & {$[26]$} \\
\hline 12. & $52 \%(1 \mathrm{wt} \%, 600 \mathrm{~nm})$ & $2 \mathrm{~mm}$ & 1 or $2 \mathrm{wt} \%$ & $\mathrm{Al}_{2} \mathrm{O}_{3}(96 \mathrm{~nm})$ & {$[27]$} \\
\hline 13 & $87 \%(600 \mathrm{~nm}, 15 \mathrm{wt} \%)$ & $0.12-0.29 \mathrm{~mm}$ & $0-15 \mathrm{wt} \%$ & $\mathrm{Al}_{2} \mathrm{O}_{3}$ & {$[28]$} \\
\hline
\end{tabular}


nanocomposites, i.e. materials in which the reinforcing component is dispersed to single nanoparticles, these composites should have the same transparency as the neat matrices since the single particles are too small to scatter. The reduction in transparency (Table 1) means that the particles in the matrix are much larger, approaching the size of the wavelength of the light used (500-600 nm), i.e. one deals practically with large aggregates of nanoparticles.

The described situation was also discussed in a very recent review [29] on transparent polymer nanocomposites with emphasis on their synthesis and advanced properties. The review comprises the following text as a general statement: 'The dispersion of particles and their affinity with the matrix are crucial parameters that closely control global properties of nanocomposites. For optimal transparency, nanocomposites require particles with dimensions $D$ very small compared to the wavelength $\lambda(D / \lambda<1)$. This condition can only be respected if primary particles are synthesized in such dimensions and if aggregation is avoided. A challenge for nanocomposite fabrication is to incorporate well-dispersed isolated particles into the polymer matrix and to improve interfacial interactions between matrix and fillers. However, due to their high specific surface area and surface interactions often involving polar groups located at the surface, nanoparticles have a strong tendency to aggregate' [29].

A peculiarity of this review article [29] is that the transparent nanocomposites are categorized according to the other targeted property (mechanical performance, thermal stability, barrier properties, and others). The other peculiarity is that contrasting the studies summarized in Table 1, where the transparency for one wavelength only is studied, in [29] the cases cover quite a large interval of wavelengths and for this reason, the transparency is presented also as an interval usually between 5-40 and 70-95\% [29]. In Table 2 are listed some examples of transparent nanocomposites with various matrices and nanofillers indicating the size of the used nanoparticles as fillers as well as the interval of transparency measured with lights of a different wavelength. In addition to the completely transparent matrices as PMMA, PS, and PC the poly(ethylene terephthalate) (PET) is included.

It is quite evident from Table 2 that the transparency capacity of the polymer nanocomposites covers a rather wide percentage interval depending on the wavelength of the used light. This dependence is much better expressed in Figure 1 where the transparency is plotted as a function of the wavelength of the light used.

As seen in Figure 1, generally, the transmittance increases with the rise of the wavelength. It is the smallest for the shortest wavelengths (below $350 \mathrm{~nm}$ ). The PC-R- $\mathrm{Al}_{2} \mathrm{O}_{3}-2 \%$ nanocomposite film with PC matrix and $2 \mathrm{wt} \%$ of nano-size $\mathrm{Al}_{2} \mathrm{O}_{3}$ (Figure 1, curve $\mathrm{f}$ ) is less transparent over most of the wavelength range for visible light. The authors [26] explain this observation by the presence of large agglomerates of raw alumina nanowhiskers in the composite film, resulting from poor compatibility with PC matrix. These large aggregates have comparable sizes to the wavelength of visible light $(380-750 \mathrm{~nm})$, which would

Table 2. Transparent polymer nanocomposites.

\begin{tabular}{|c|c|c|c|c|c|c|}
\hline$\#$ & Polymer matrix & $\begin{array}{c}\text { Nanoparticles size } \\
{[\mathrm{nm}]}\end{array}$ & $\begin{array}{c}\text { Transparency (UV-Vis) } \\
{[\%]}\end{array}$ & Thickness & $\begin{array}{l}\text { NP content } \\
{[w t \%]}\end{array}$ & Ref. \\
\hline 1. & $\mathrm{PC}$ & Coated $\mathrm{Al}_{2} \mathrm{O}_{3}(96$ or $30 \mathrm{~nm})$ & From 5 to 60 & $2 \mathrm{~mm}$ & 1 to 2 & [27] \\
\hline 2. & $\mathrm{PC}$ & $\mathrm{Al}_{2} \mathrm{O}_{3}($ dia. $2-4 \mathrm{~nm}, l=2800 \mathrm{~nm})$ & From 50 to 80 & $0.15 \mathrm{~mm}$ & 2 & {$[26]$} \\
\hline 3. & PET & $\mathrm{TiO}_{2}$ & From 5 to 40 & $80 \mu \mathrm{m}$ & 1 to 5 & [29] \\
\hline 4. & PMMA & Clay & From 78 to 90 & $100 \mu \mathrm{m}$ & 1 to 5 & {$[30]$} \\
\hline 5. & PMMA & $\mathrm{ZrO}_{2}(3.8 \mathrm{~nm})$ & From 70 to 85 & $1 \mathrm{~mm}$ & Up to 7 & [31] \\
\hline 6. & PMMA & $\mathrm{ZnS}(3 \mathrm{~nm})$ & From 25 to 90 & $4 \mathrm{~mm}$ & 5 to 15 & [32] \\
\hline 7. & PMMA & $\mathrm{SiO}_{2}$ & From 30 to 90 & $\sim 1 \mathrm{~mm}$ & 4 to 8 & [33] \\
\hline 8. & PS & (grafted) & From 20 to 70 & $70 \mu \mathrm{m}$ & Up to 1.05 & [34] \\
\hline 9. & PS & $\mathrm{TiO}_{2}$ & From 5 to 80 & $100-200 \mu \mathrm{m}$ & 5 to 20 & [35] \\
\hline 10. & PMMA & Clay & From 10 to 68 & $3 \mathrm{~mm}$ & 0.39 to 4.60 & [36] \\
\hline 11. & PS & $\mathrm{ZnO}(5-35 \mathrm{~nm})$ & From 40 to 80 & $64-68 \mu \mathrm{m}$ & 0 to 9 & [37] \\
\hline 12. & PS & $\mathrm{CeO}_{2}(18 \mathrm{~nm})$ & From 60 to 80 & $2.5 \mu \mathrm{m}$ & 5 & [38] \\
\hline 13. & PMMA & $\mathrm{TiO}_{2}(33 \mathrm{~nm})$ & From 55 to 80 & $2.35 \mu \mathrm{m}$ & 1 to 5 & [39] \\
\hline 14. & PS & Doped $\mathrm{CeF}_{3}(42 \mathrm{~nm})$ & From 30 to 75 & $0.1 \mathrm{~mm}$ & Up to 20 & [40] \\
\hline
\end{tabular}




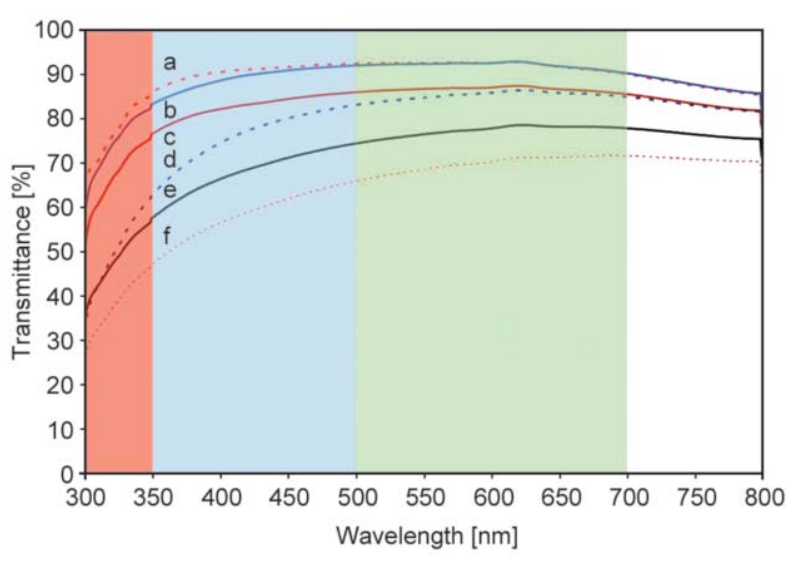

Figure 1. UV-visible spectra of: (a) extruded plain $\mathrm{PC}$, (b) $\mathrm{PC}-\mathrm{Al}_{2} \mathrm{O}_{3}-\mathrm{RT}-0.5 \%$, (c) plain PC, (d) PC$\mathrm{Al}_{2} \mathrm{O}_{3}-\mathrm{RT}-1 \%$, (e) $\mathrm{PC}-\mathrm{Al}_{2} \mathrm{O}_{3}-\mathrm{RT}-2 \%$, (f) PC-R$\mathrm{Al}_{2} \mathrm{O}_{3}-2 \%$ (Adapted from: Hakimelahi H. R., $\mathrm{Hu}$ L., Rupp B. B., Coleman M. R.: Synthesis and characterization of transparent alumina reinforced polycarbonate nanocomposite. Polymer, 51, 2494 2502 (2010), [26]).

result in scattering at the interface between aluminarich and polymer-rich phases [41].

The other important conclusion from Figure 1 is that the transparency for the shorter wavelengths is much lower. This means that in the nanocomposite materials are dominated by particle aggregates with dimensions between 100 and $300 \mathrm{~nm}$, which do not scatter anymore if the wavelengths increase to 500 $800 \mathrm{~nm}$, and the transparency increases drastically too (above $70 \%$ ) (Figure 1). At the same time, the typical sizes of the inorganic nanomaterials are of a couple of nm (Tables 1 and 2) and the aggregates with sizes of 100-300 nm should comprise many tens of nanoparticles, which means, the composite material does not consist of individual nanoparticles. This situation is illustrated in Figure 2 as well, where $\mathrm{PC}$ is melt-blended with nano-sized $\mathrm{Al}_{2} \mathrm{O}_{3}$ with sizes of 96 or $30 \mathrm{~nm}$, and the used light is of wavelength in the interval 300 and $700 \mathrm{~nm}$.

From Figure 2 it is easy to see that at a wavelength shorter than $400 \mathrm{~nm}$ the transparency is extremely small (up to $25 \%$, Figure 2 curve b) or approaching zero (Figure 2, curves c, d, e). Even for $\lambda=500$ $700 \mathrm{~nm}$ it approaches $35-40 \%$ transparency only (Figure 2, curves c, d, e). These observations indicate that the nanoparticles do not exist anymore in the PC matrix as individual particles but as their aggregates with sizes of a couple of hundreds of $\mathrm{nm}$. Possibly, this is the reason why the transmittance does not depend on the size of individual nanoparticles. The transmittance is the same for particles of

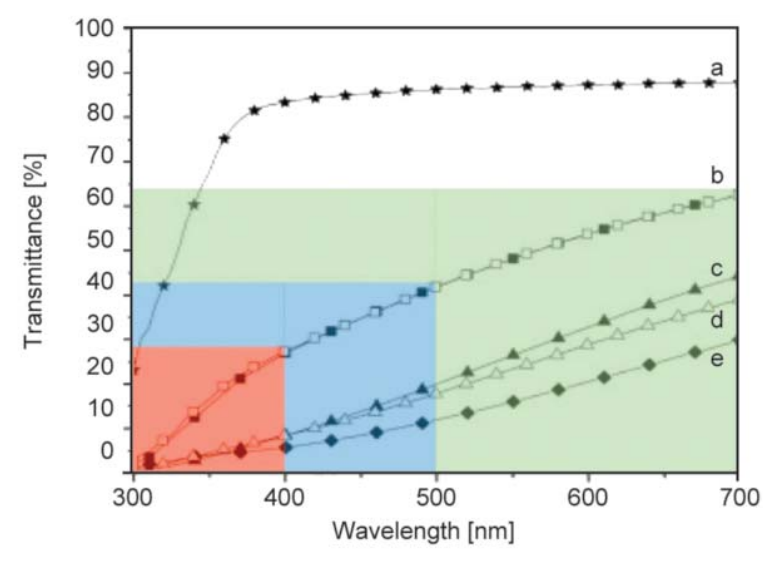

Figure 2. Light transmittance at various wavelength of the light used of melt compounded $\mathrm{PC} / \mathrm{Al}_{2} \mathrm{O}_{3}$ nanocomposites: a) PC neat resin, b) PC with $1 \mathrm{wt} \%$ nanoparticles of $96 \mathrm{~nm}$ subjected to centrifuge treatment, as well as PC with $1 \mathrm{wt} \%$ nanoparticles of $30 \mathrm{~nm}$ subjected to centrifuge treatment, c) PC with $2 \mathrm{wt} \%$ nanoparticles of $96 \mathrm{~nm}$ subjected to centrifuge treatment, d) PC with $2 \mathrm{wt} \%$ nanoparticles of $30 \mathrm{~nm}$ subjected to centrifuge treatment, e) PC with $2 \mathrm{wt} \%$ nanoparticles of $96 \mathrm{~nm}$ not subjected to centrifuge treatment (Adapted from Chandra A., Turng L-S., Li K., Huang H-X.: Fracture behavior and optical properties of melt compounded semitransparent polycarbonate (PC)/alumina nanocomposites. Composites Part A: Applied Science and Manufacturing, 42, 1903-1909 (2011), [27]).

30 or $96 \mathrm{~nm}$ and depends on their concentration only (Figure 2, curves b-e).

It seems important to mention that the transparent nanocomposites discussed in [29] are prepared using different fabrication methods aiming at proper nanoparticle dispersion as well as perfect matrix-filler adhesion. The methods used are: (i) blending methodology (melt blending or solution blending) [27, 30, $35,42-66]$; (ii) in situ polymerization in the presence of inorganic particles [67-81]; (iii) in situ particle formation in preformed polymer matrix [82112]; (iv) simultaneous in situ particle and polymer matrix formation [113-124]; (v) casting of polymer solution loaded with core-shell nanoparticles [52, 120, 121, 125-132]. However, these techniques are very complex. They use solvents, high temperatures, additional chemicals, and others, making the control of particle sizes and their distribution uneasy. For example, the very promising and attractively looking method of simultaneous in situ particle and polymer matrix formation used for the preparation of transparent $\mathrm{PMMA} / \mathrm{SiO}_{2}$ nanocomposites via polymerization of w/o microemulsions [121] did not justify the expectations. It has been reported [121]: ' .... that 
the transmittance of the composite $\left(1.33 \mathrm{wt} \% \mathrm{SiO}_{2}\right)$ is very close to that of pure PMMA. A significant loss in transparency is detected only below $\lambda=$ $500 \mathrm{~nm}$. For higher filler contents, a loss of transmittance is also observed in the visible region (at $6.67 \%$ filler, the transmittance is only $33 \%$ and the products are turbid). The sharp drop in transmittance is due to the instability of the particle-containing microemulsion at higher filler contents and the formation of agglomerates during the polymerization and hydrolysis of the precursor. The reduced transmittance is also observed in MMA-based silica-free microemulsions after polymerization. The microemulsion used for the generation of a $4 \%$ $\mathrm{SiO}_{2}$-containing composite has a transmittance of only $78 \%$ after polymerization, whereas the polymerized microemulsion corresponding to the $6.67 \%$ $\mathrm{SiO}_{2}$-containing composite only has a transmittance of $50 \%(600 \mathrm{~nm}) \ldots$..' [121].

In addition to the dispersion problem, let us not forget some basic knowledge of composite science regarding the effect of reinforcing particle shape on the enhancement of mechanical properties of composite materials. Some of the properties, e.g. elasticity modulus $E$, microhardness $H$ [133] of polymers, and their composites obey the Rule of mixture.

Contrasting $E$ and $H$, the tensile strength $\sigma$ does not obey the Rule of mixture. What is more, its enhancement can be observed only if the reinforcing particles are strongly anisometric, that is, their aspect ratio must not be smaller than 6 , as demonstrated by modeling $[134,135]$ and experimental $[136,137]$ studies. This situation is illustrated in Figure 3 for low density polyethylene (LDPE) reinforced with glass fibers (Figure 3, second column) or glass spheres (Figure 3, third column) used in equal amounts [136].

From these considerations follows a quite interesting conclusion regarding the reinforcing potential of nano-size materials whose particle have an aspect ratio close to 1, i.e., their length and thickness are almost of the same size. Considering that practically all inorganic nanomaterials (rare exceptions are the nanowhiskers) are isodiametric (with aspect ratios close to 1 , Tables 1 and 2), it follows that this fact only is a good reason for their modest mechanical performance experimentally observed. Obviously, this is the main reason for the poor mechanical properties of transparent nanocomposites prepared via methods avoiding mechanical blending of the matrix polymer and the reinforcing nanomaterial [42-132] - the created

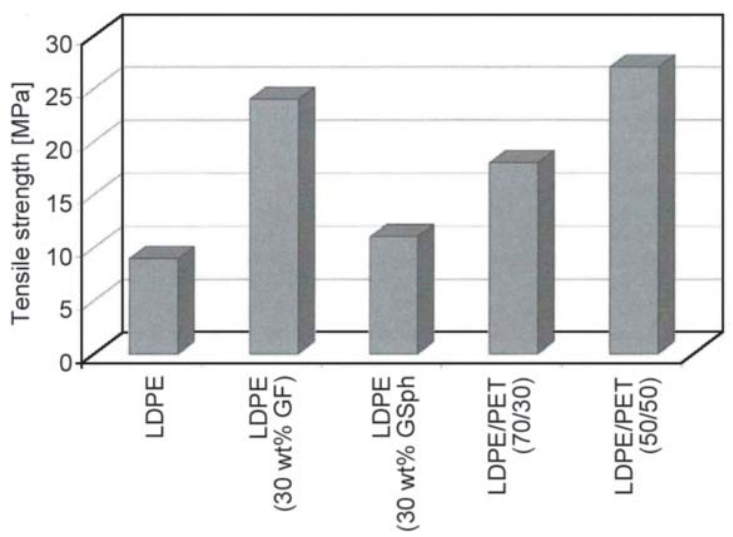

Figure 3. Tensile strength of injection molded samples from recycled PET (bottles) and LDPE as compared to neat LDPE and LDPE reinforced by short-glass fibers (GF) or glass spheres (GSph) [136].

in this way nanoparticles are always isodiametric and never fiber-like [42-132].

Summarizing, we conclude that to observe a reinforcing effect, we must use reinforcing material in the form of fibers. For manufacturing of polymer nanocomposites good candidates in this respect are the electrospun fibers or, even better, the carbon nanotubes (CNTs), or nanowhiskers but in these cases, we face again the non-soluble problem of the proper dispersion, dispersion in the matrix to single individual nanoparticles without any agglomeration! However, dispersion of non-spherical nanoparticles is a very challenging issue and sometimes may lead to deterioration of nanoparticles during the mixing process. For instance, as-synthesized CNTs form agglomerates consisting of severely entangled nanorods which should be fully disentangled during the mixing process, that is not easily met for polymer-CNT nanocomposites. It was shown that the dispersion of CNT is achieved by fragmentation of bigger agglomerates to smaller agglomerates mainly through the rupture mechanism during melt mixing process [138]; however, the shear stresses exerted on CNT agglomerates cause a significant fiber breakage during the rupture of agglomerates which seriously decreases the effectiveness of CNT $[138,139]$. Moreover, in many systems, at high nanotube concentrations, where the aggregation is developed, the effects of poor dispersion are generally accompanied by a decrease in strength and modulus [140].

Coming back to the terminological issue it should be noticed that it is hardly correct to classify the abovediscussed composites as 'nanocomposites' because 
they, in fact, belong to the category of microcomposites. If we agree with such a statement, a quite important conclusion can be derived regarding the answer to the very basic question about the drastic difference between expected and observed mechanical properties of the polymer nanocomposites prepared via blending matrix and reinforcement. These materials do not justify the expectations derived for nanocomposites concept because they are not nanocomposites - they are microcomposites. The situation is quite interesting because it could be considered from its reverse side - the lack of agreement between observed and predicted mechanical properties support the conclusion that these composites are not of nano-type. Moreover, this can be proven if we succeed to prepare real polymer nanocomposites and measure their mechanical properties as it will be demonstrated in the further paragraphs of this review.

\section{The dispersion - a global problem in chemistry and in material science}

The practical needs of materials with new or improved properties lead to blending two or more different materials in order to drastically improve the properties of one of the components or to obtain a blend with new properties. For a long time this approach has been used in metallurgy and since the middle of the last century, it has been introduced to polymer material science.

Usually, the matrix component is dominating in amount, and it is presented in a continuous form while the other minor component(s) is in form of small (micro- or nano-range) particles or fibers. Such a dispersed system has three fundamental aspects: (i) dispersion, (ii) distribution, and (iii) stabilization.

Distribution is the way the particles fill the space, whereas dispersion is the way these particles are agglomerated or not. With a good distribution, each particle is as far as possible from its nearest neighbor, so that space is homogeneously filled with particles. With a good dispersion, all particles have the same shape and size, as small as possible, as no agglomerates exist. Therefore, it is quite possible to have good distribution but poor dispersion, or poor distribution and good dispersion, as schematically demonstrated in Figure 4. If particles are conducting and if you want a high conductivity, you should indeed prefer the situation in which particles can make a conducting path by touching each other, but agglomeration

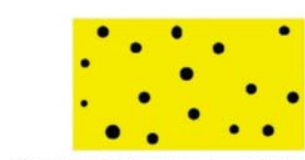

Good distribution, poor dispersion a)

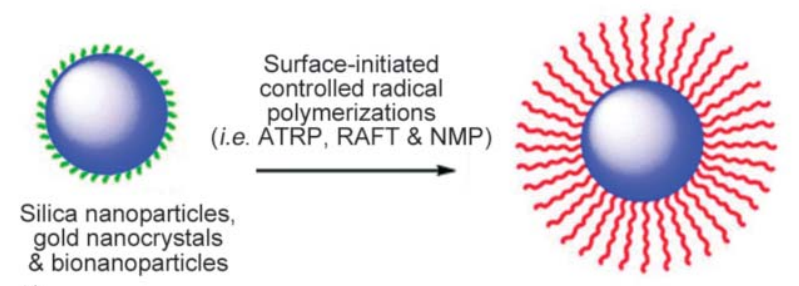

c)

Figure 4. Schematic: a) good distribution, poor dispersion, b) good dispersion, poor distribution, c) stabilization. (Adapted from a) and b) Celzard A., McRae E., Deleuze C., Dufort M., Furdin G. Mareche J. F.: Critical concentration in percolating systems containing a high-aspect-ratio filler. Journal of Physical Review B, 53, 6209-6214 (1996) ; c) Wu L., Glebe U., Boeker A.: Surface-initiated controlled radical polymerizations from silica nanoparticles, gold nanocrystals, and bionanoparticles. Polymer Chemistry, 6, 5143-5184 (2015), [142]).

should be avoided as many particles would be useless because behaving as dead ends for the conducting path.

Regardless of how the dispersed system is prepared, it needs to be stabilized since the dispersed particles tend to agglomerate. How the stabilization could be done is shown in Figure 4c.

The stability of a polymer dispersion is its most important property. There are three different mechanisms that impart stability to polymer dispersions: (i) the electrostatic stabilization with either positive or negative charges on the particle surface arising from the initiator or ionic comonomers, (ii) the steric stabilization with adsorbed or tethered polymers that are soluble in the dispersion medium, and (iii) the electrosteric stabilization that is either a simple combination of electrostatic and steric stabilization or a stabilization with adsorbed or tethered polyelectrolytes. The search for new stabilizers is an important area in colloid research. A hairy particle stabilized by polymeric surfactants (Figure 4c) is illustrating a topic of such research. The preparation of model particles with only one kind of stabilization - exclusively steric or exclusively electrostatic stabilized particles - is another goal of these activities [143].

Let us remember what thermodynamics says about dispersed systems. 
It is well-known that dissolution is one of the cases of dispersion, that is, the dispersing of one component into another one. The multi-component systems, in which some of the components are in a dispersed state, are dispersed systems. Depending on the degree of dispersion, they can be colloid systems or true solutions. True solutions are dispersed systems in which the components are dispersed as molecules, atoms, and ions. Consequently, the true solution represents a molecularly dispersed system distinguished by a couple of characteristic features such as affinity of components, constant concentration in the time, homogeneity (one-phase systems!), and thermodynamic stability.

Dissolution as a self-running equilibrium process is possible only if its progress is paralleled by a decrease in the free energy $F$ (at $V$ : constant and $T$ : constant) or by reducing the isobar-isothermal potential $G$ (at $p$ : constant and $T$ constant).

The change in free energy $\Delta F$ at $T$ : constant obeys the Equation (1):

$\Delta F=\Delta H-T \Delta S$

According to this equation, dissolution is possible at constant temperature both when the enthalpy of the system $\Delta H$ decreases and when the entropy $\Delta \mathrm{S}$ increases.

It is known that the dissolution of polar polymers in polar solvents takes place with heat development, that is, the heat effect $(Q)$ is positive. From the other side, $\Delta H=-Q$, consequently $\Delta H<0$ and $\Delta F<0$. The heat development during dissolving is associated with the formation of strong bonds between molecules of solvent and those of polymer (for example, due to the formation of H-bonds). By the way, this positive heat effect can explain the spontaneous dissolution of polar polymers into polar solvents.

The experiments on solutions of non-polar polymers in non-polar solvents demonstrated that the degree of solvation is negligibly small, and the heat effect tends to be zero. In case of such solutions $\Delta H=0$ $(Q=0)$. Dissolution with zero or negative heat effect can be explained only by an increase in the entropy of the system during the mixing of solution components and their mutual diffusion.

In the case when the solution is ideal, that is, when the molecules of a dissolved substance do not interact, it is possible to calculate the entropy increase of the system as a result of mixing getting the ideal entropy of mixing, $S_{\text {id }}$. For an ideal solution, the change in isobar-isothermal potential $\Delta G$ (called also free energy at constant pressure or Gibbs free energy, on whose change depends the possibility for realization of the process) can be expressed as (Equation (2)):

$\Delta G_{\text {mix }}=R T\left(n_{1} \ln x_{1}+n_{2} \ln x_{2}\right)$

where $R$ is the gas constant, $T$ is absolute temperature, $n_{1}$, and $n_{2}$ are the number of moles of the components 1 and 2, respectively, and $x_{1}$, and $x_{2}$ are molar parts of components 1 and 2, respectively [e.g., $\left.x_{1}=n_{1} /\left(n_{1}+n_{2}\right)\right]$. Using the last equation, it is easy to express the change in the ideal mixing entropy $\Delta S$ considering that $\Delta G=\Delta H-T \Delta S$ and that $H=0$ (ideal solution, i.e., $\Delta Q=0$ ) (Equation (3)):

$$
\Delta S_{\text {mix }}=-R\left(n_{1} \ln x_{1}+n_{2} \ln x_{2}\right)
$$

Since the molar parts $x$ are always smaller than 1 , their logarithms are negative. Consequently, the expression in the bracket in Equation (3) remains negative in all cases, and $\Delta S_{\text {mix }}$ is always positive. This means that mixing always results in entropy increase, that is, an increase of degrees of freedom. In other words, the entropy change during mixing is such that it always results in the spontaneous mixing of components in any ratio.

While the change of ideal mixing entropy can be calculated also by means of a statistical approach using a lattice model, Flory and Huggins suggested simultaneously and independently (in 1942) another, somewhat different (but not free of some empiricism) approach for solving the same problem. The FloryHuggins theory has great importance for explaining the severe deviations of polymer solutions from the ideal laws [144].

Unfortunately, the above thermodynamic considerations cannot be applied to polymer dispersions being of interest for material science because they are composed of components that are not thermodynamically miscible, i.e. they are not molecularly dispersed systems. For this reason, contrasting the true solutions, they are characterized by the following characteristic features:

- lack of affinity of components resulting in the lack of self-dispersing process,

- lack of constant concentration in the time due to the continuous dephasing and/or sedimentation, 
- lack of homogeneity (not being one-phase systems!) leading to dephasing, and

- lack of thermodynamic stability resulting in the need of stabilization.

The preparation of dispersed systems for the needs of polymer material science and technology is a task somewhat different from the preparation of polymer solutions - work is needed to convert the bulk material into micro- or nano-sized particles, additional work has to be invested for dispersing these particles into polymer matrix, and finally, a stabilization is needed to keep the desired dispersity. These tasks have been attacked since the emergence of colloid chemistry (middle of the $19^{\text {th }}$ century). In fact, the areas of 'understanding the governing parameters that control particle dispersion', 'synthetic methodologies to modify particle interfaces', the 'role of interface chemistry on particle dispersion', 'transparent nanocomposites'. etc. have seen tremendous advancements during the recent decades. Examples of these advances include Flory lattice models and computer simulations that have an advanced understanding of the role of structural and interaction parameters on the stability of particle-in-polymer dispersions. Surface-initiated controlled polymerizations have shown to facilitate stable dispersions and transparent materials. This is not to say that all problems have been solved; however, the purpose of this section is to provide readers with state-of-the-art and more nuanced overview of the advances and limitations of this field.

The superior properties of nanoparticles themselves do not assure high-performance polymer nanocomposites at all; however, morphological characteristics of corresponding polymer nanocomposites have also a prime impact on the final properties. Basically, the dispersion state of nanoparticles in polymer matrices is dominated primarily by mixing processes; however, surface characteristics of nanoparticles can also facilitate the breakdown of the agglomerates resulting in better dispersion. Surface characteristics can be tailored basically by suitable surface modification of nanoparticles which can be helpful to overcome its incompatibility with hosting polymer and to obtain strong polymer/nanoparticles interfacial interaction [16].

Nowadays it is well recognized that the mixing of polymers and nanoparticles is paving the way for engineering flexible composites that exhibit advantageous electrical, optical, or mechanical properties
[145]. In a study on understanding the microstructure of particle dispersion in confined copolymer nanocomposites [146] it has been shown that, under the condition of confinement, particles display different distributions near the solid surfaces, in the microdomains of two blocks, and at the microphase interfaces. The final dispersion depends on the balance between the enthalpic contribution arising from the particle-segment attraction as well as the entropydriven depletion attraction induced by the polymer conformation and the confinement environment. For the systems in which particles weakly attract one block but repel another block, particle dispersion can be enhanced by the increasing confinement effect, and the enhancement becomes more evident as the size asymmetries of particles and two blocks increase. If the attraction increases, however, particle dispersion declines as the confinement effect increases [146]. At the same time, as stated in the same publication [146], confinement induced particle dispersion in copolymer films is far from being understood. For a confined copolymer nanocomposite, because of the microphase separation of the copolymer and the physically confined environment, the state of particle dispersion becomes more complex [146]. In the attempts for synthetic modification of particle interfaces, the emulsion polymerization is the most widely used synthetic technique [147]. Emulsion polymerization, as a traditionally leading synthesis technique, has been widely used for the synthesis of polymeric particles [148]. However, spherical particles are often formed because of interfacial tension [149], which limits flexibility in tuning the topology and chemistry of the particles. Achieving large-scale synthesis of uniform Janus particles with tunable topology and surface chemistry by emulsion polymerization remains a great challenge [147].

Dispersion polymerization is a convenient procedure to form larger solid particles. Uniform-sized polymer beads with diameters between 0.1 and $10 \mu \mathrm{m}$ are finding an ever-increasing role in several coatings, electronics, microelectronics, biomedical, and information technology applications. Particle size control and narrow size distribution are critical parameters for most of these applications. Dispersion polymerization is generally recognized as a type of precipitation polymerization, conducted in the presence of a polymeric stabilizer that is soluble in the reaction medium [150]. As already mentioned, because of their unique sizedependent electrical, magnetic, mechanical, optical, 
and chemical properties, which widely differ from those of the bulk materials, nanoparticles have already become an indispensable material for many industrial fields. Nanoparticles have different surface structures and surface interactions from those of the sub-micron sized particles; in particular, they show a much stronger aggregation tendency. For applications in functional materials and products, it is important to develop techniques for controlling the dispersion and aggregation of nanoparticles. Dispersion of nanoparticles in aqueous media can well be modeled with the theory by Deryagin, Landau, Verwey and Overbeek (DLVO). However, it is still a challenging task to manage high-concentration nanoparticle suspensions in organic media. Surface modification of nanoparticles is one of the most common methods to improve the dispersion stability of nanoparticles. It requires a design of the surface structure based on the type of nanoparticles and the liquid media.

In a review of new methods of surface chemical modification, dispersion and electrophoretic deposition of metal oxide particles [151] it is reported that polyaromatic dyes can be used as efficient co-dispersants for oxide materials, carbon nanotubes and graphene for the fabrication of composite films by electrophoretic deposition. The use of new dispersants with strong interfacial adsorption and multifunctional properties has driven the development of advanced composites, containing metal oxide nanoparticles, conductive polymers, carbon nanotubes, graphene, polyelectrolytes and other materials. Colloidal and interface chemistry of new dispersing agents is emerging as a new area of technological and scientific interest [151].

Surface modification using polymer brushes has become a powerful approach to tailor the chemical and physical properties of interfaces. It has given rise to great advances in surface and interface engineering [152]. In the most general sense, polymer brushes are defined as thin polymer films, in which the individual polymer chains are tethered by one chain end to a solid interface. Depending on the density at which polymer chains are anchored to the surface and their molecular weight, surface-anchored polymer chains can adopt various conformations, from the so-called 'mushroom' or 'pancake' regime at low grafting densities to the high density 'brush' regime [152]. In a review on the state of the art of growing polymers from nanoparticles using surface-initiated controlled radical polymerization techniques [142] is highlighted that in recent years, core/shell nanohybrids containing a nanoparticle core and a distinct surrounding shell of polymer brushes have received extensive attention in nanoelectronics, nanophotonics, catalysis, nanopatterning, drug delivery, biosensing, and many others. From the large variety of existing polymerization methods on the one hand and strategies for grafting onto nanoparticle surfaces, on the other hand, the combination of grafting-from with controlled radical polymerization techniques has turned out to be the best suited for synthesizing these welldefined core/shell nanohybrids and is known as surface-initiated controlled radical polymerization. Most common among these are surface-initiated atom transfer radical polymerization (ATRP), surface-initiated reversible addition-fragmentation chain transfer (RAFT) polymerization, and surfaceinitiated nitroxide-mediated polymerization (NMP) [142]. An example of such a process is schematically shown in Figure 4c.

In a publication on high-transparency polymer nanocomposites enabled by polymer graft modification of particle fillers [153] it is stated that the ability to augment the physical properties of polymer materials while maintaining their advantageous processability characteristics has rendered polymer nanocomposites one of the most actively researched areas in the field of polymer materials [154-158]. One reason for the interest in nano-sized filler particles is the opportunity to achieve desired property enhancements without compromising auxiliary characteristics such as optical transparency [154]. In the absence of optical absorption, the transparency of composite materials is determined by the scattering of light from dielectric (i.e., structural or compositional) heterogeneities. For the particular case of nanocomposites based on transparent polymer host materials (e.g., amorphous thermoplastics or resins) the optical transparency is hence determined by the light scattering of particle inclusions [154].

The role of polymeric ligands on the optical transparency of polymer-matrix composites is analyzed by evaluating the effect of surface modification on the scattering cross-section of particle fillers in uniform particle dispersions. For the particular case of poly (styrene-r-acrylonitrile)-grafted silica particles embedded in poly(methyl methacrylate), it is shown that the tethering of polymeric chains with appropriate optical properties (such as to match the effective 
refractive index of the brush particle to the embedding matrix) facilitates the reduction of the particle scattering cross-section by several orders of magnitude as compared to pristine particle analogs [153]. A challenge for the generation of transparent nanocomposites is to develop an integrated synthesis strategy adapting particle generation, surface modification, and integration inside the polymer. Surface grafting using polymerizable surfactants or capping agents allows for linking the particles to the polymer. Novel techniques such as in situ polymerization and in situ particle processing are beneficial to avoid aggregation of inorganic particles inside the polymer matrix [159].

The fabrication of transparent nanocomposites has been the subject of many efforts to develop methods to limit aggregation. To address this challenge, several methods have been implemented to control the polymerization process, the nanoparticle synthesis, and the polymer-nanoparticle interface together with the polymer casting or processing. The main methodologies developed to fabricate transparent nanocomposites are discussed according to four main categories: the blending of nanoparticles and polymer, the in-situ polymerization in the presence of preformed nanoparticles, the in-situ nanoparticle synthesis in a pre-formed polymer matrix, and finally the simultaneous polymerization and in-situ nanoparticle synthesis.

Polymer nanocomposites for optical applications require high optical transparency at high filling ratios of nanoparticles. The nanoparticles provide optical functionality but unfortunately have a strong tendency to aggregate in polymer matrices leading to strong turbidity and reduced optical transmission, particularly at high filling ratios. A general route to non-aggregated highly filled, optically transparent polymer nanocomposites based on using nanoparticles was reported in [164]. The particles have been coated with polymers forming spherical brush-like layers, as schematically shown in Figure 4c, providing thermodynamic miscibility with the polymer matrix over the complete range of nanoparticle volume fractions. The polymers are attached via a versatile ligand exchange procedure which enables us to prepare a wide range of optically transparent polymer nanocomposites up to weight fractions of $45 \%$. This is demonstrated for a broad range of metal and semiconductor nanoparticles in optically transparent polymer matrices relevant for selective light/UV absorption, photoluminescence, and high/low refractive index polymer materials [160].

In the end let me mention a review article on developments in 4D-printing covering current smart materials, technologies, and their applications [165] as a demonstration of the achievements of polymer material science and technology. Recent advances in additive manufacturing, commonly known as three-dimensional 3D-printing, have allowed researchers to create complex shapes previously impossible using traditional fabrication methods. A research branch that originated from 3D-printing called four-dimensional 4D-printing involves printing with smart materials that can respond to external stimuli. 4D-printing permits the creation of on-demand dynamically controllable shapes by integrating the dimension of time. Recent achievements in synthetic smart materials, novel printers, deformation mechanisms, and mathematical modeling have greatly expanded the feasibility of 4D-printing [161].

\section{Manufacturing of polymer nanofibers}

Since the beginning of the last century exists a technique for converting many polymers into nanofibrillar state using their solutions or melts. Electrospinning was first observed by Rayleigh in 1897, studied further by Zeleny and patented by Formhals in 1934 [162]. Electrospinning has been widely used in the past decades to produce nanofibres from a variety of different polymers $[9,163]$ with application in regenerative medicine [164].

Nowadays, electrospinning is used in hundreds of labs worldwide because of its elegance, not expensive setup and the fascinating electron microscopic images of the nanofibers obtained, which can be seen in some 2000 papers published per year. At the same time, this attractive technique has the disadvantage that not so much can be done practically with the fine nanofibers because of the not easy handling of the spun material. Even more complicated is the situation if one tries to use the nanofibers as reinforcement for polymer nanocomposites - the dispersion problem is becoming practically non-soluble not only because of the difficulties stemming from the nano-sizes but also due to the network character of the mat.

Using various techniques, the local molecular orientation of the polymer chains within the fibers has been measured and found that the degree of orientation of the polymer chains with respect to the fiber axis increases with decreasing fiber diameters [165-169]. 
Although it has been shown by various researchers that electrospinning can induce some level of chain orientation in fibers based on flexible chain polymers, these levels are often rather low [165]. Of particular importance for the issue discussed are the results of small-angle neutron scattering (SANS) studies on chain extension in electrospun polystyrene fibres [170]. These results are summarised in [165] in the following way: '...The SANS was used to quantify the size and shape of the chain conformation in electrospun fibers of deuterated atactic polystyrene prepared from solutions. Although the orientation parameter $\left\langle P_{2}\right\rangle$ was found to increase with increasing collecting speed, the maximum value of about 0.15 was well below the orientation parameter expected for high-performance polymer fibers with values typically approaching 1 . When the tangential velocity of the rotating collector was greater than the flight velocity of the fibers some degree of orientation of the polymer coils was induced. However, even at the highest collector speeds the ratio of the radii of gyration increased only by $20 \%$ from for bulk $(17 \mathrm{~nm})$ to fibers $(20 \mathrm{~nm})$, showing limited coil deformation. As the diameters of these fibers were much greater than the polystyrene radius of gyration these effects can be solely contributed to flow-induced orientation, excluding size or confinement effects as a result of nano-sized fiber diameters'.

These results are of paramount importance. They demonstrate that the electrospun extremely fine cylindrical formations with diameters in the nano range are comprised of isotropic material and they even hardly could be called polymeric fibers. The polymer fibers, e.g. the synthetic ones, comprise highly extended macromolecules aligned parallel to each other. Such a molecular structure results in superior mechanical properties as compared with the same polymer being in an isotropic non-oriented state. The lack of molecular orientation in the electrospun material is obviously the main reason for its poor mechanical performance as discussed below.

Regardless of the existence of the problem with the proper dispersion, electrospun nanofibers are hardly suitable reinforcing material because of their inferior mechanical properties. As stated in [163], the mechanical properties of most electrospun polyamide and polyester fibers are not comparable with conventional microfibers manufactured by melt-spinning, which again can be ascribed to the low degree of chain orientation in these as-spun nanofibers and the absence of a post-drawing step in the electrospinning process. In fact, in many cases, the properties of electrospun fibers are even inferior to that of the bulk polymer, as can be concluded from the data displayed in Table 3. This situation can be attributed also to factors, such as residual solvent, plasticization, and porosity [165].

In conclusion, the electrospun polymer nanofibers cannot be used as reinforcement for the manufacturing of polymer nanocomposites because their mechanical properties are worse than those of the polymer matrix (Table 3). It turned out that 'nano-sized' does not mean necessarily 'superior mechanical performance'. The size alone is not enough, something more is needed!

What is more, it follows that these famous electrospun nanofibers do not belong to the family of the real polymeric fibers, that is to the family of the cylindrical

Table 3. Mechanical properties of electrospun polyamide (PA) and poly(ethylene terephthalate).

\begin{tabular}{|c|c|c|c|c|c|}
\hline$\#$ & Polymer & Sample & $\begin{array}{c}\text { Modulus } \\
\text { [MPa] }\end{array}$ & $\begin{array}{c}\text { Strength } \\
\text { [MPa] }\end{array}$ & Ref. \\
\hline 1. & PA 6 & Nonwoven nanofiber mat & $34 \pm 2$ & $7.2 \pm 0.5$ & {$[171]$} \\
\hline 2. & PA 6,6 & Nonwoven nanofiber mat & $21 \pm 1$ & $6.5 \pm 0.8$ & {$[171]$} \\
\hline 3. & PA 6 & Nonwoven nanofiber mat & 19 & 10.5 & {$[172]$} \\
\hline 4. & PA 6 & Single nanofiber & 902 & 304 & {$[172]$} \\
\hline 5. & PA 6,6 & Single nanofiber & $950 \pm 390$ & $150 \pm 49$ & {$[173]$} \\
\hline 6. & PA 6,6 & Nanofiber yarn & 1216 & 120 & {$[174]$} \\
\hline 7. & PA 6 & Single nanofiber & $1320 \pm 152$ & $78.1 \pm 6.0$ & {$[175]$} \\
\hline 8. & PA 6 & Nonwoven nanofiber mat & $418 \pm 93$ & $57.7 \pm 8.9$ & {$[176]$} \\
\hline 9. & PET & Nonwoven nanofiber mat & 60 & 3.7 & {$[177]$} \\
\hline 10. & PA $6 / 6,6$ & Bulk & $2000-2500$ & $50-80$ & {$[178]$} \\
\hline 11. & PET & Bulk & $2000-3000$ & $50-150$ & {$[178]$} \\
\hline 12. & PA $6 / 6,6$ & Single fiber & 6000 & 1000 & {$[179]$} \\
\hline 13. & PET & Single fiber & 15000 & 1100 & {$[179]$} \\
\hline
\end{tabular}


morphological formations characterized by high molecular orientation resulting in superior mechanical performance. For this reason, possibly, they have to be called 'fiber-like nanomaterials' or 'fibrous nanomaterials' or 'nanomakaroni' as suggested recently [180].

Opportunities for converting bulk polymers into nanosized materials are also offered by the new type of polymer-polymer composites, the micro- and nanofibril reinforced composites (MFCs and NFCs) developed during the last two decades [181-191].

MFCs and NFCs are comprised of a polymer with a lower melting temperature $\left(T_{\mathrm{m}}\right)$ as a matrix, reinforced with extremely thin fibrils of a higher- $T_{\mathrm{m}}$ polymer. The two basic requirements for the preparation of these two types of polymer-polymer composites are: a difference in the $T_{\mathrm{m}}$ of at least $40^{\circ} \mathrm{C}$ between the two composite components, and that the two polymers are not thermodynamically miscible [183]. An idea about the mechanical properties of MFCs based on LDPE as a matrix and PET as reinforcement can be obtained from Figure 3. The tensile strength of the LDPE/PET $=70 / 30$ (by wt) is close to that of LDPE/GF with the same composition. The LDPE/PET $=50 / 50$ (by wt) has a tensile strength higher than that of LDPE/GF $=70 / 30$ (by wt) as well as 3 times higher than that of the neat matrix (Figure 3) [182].

Detailed studies on the formation of the individual micro- and nanofibrils led to the conclusion that it takes place during the cold drawing via coalescence of the elongated droplets [185], as schematically illustrated in Figure 5.

'Cold drawing' in this case means drawing at temperatures being close to the glass transition temperature $\left(T_{\mathrm{g}}\right)$ of the reinforcing polymer. For polymer blends comprising PET as reinforcement, the drawing usually is performed at $70-80^{\circ} \mathrm{C}$. During this treatment, in addition to the transformation of spherical particles into fibrils via coalescence (Figure 5), a drastic molecular orientation takes place since, at such temperatures, the drawing goes via necking [192]. The perfect molecular orientation during the cold drawing is shown on the wide-angle X-ray scattering (WAXS) patterns displayed in Figure 6 taken from extruded PP/PET bled before and after cold drawing.

This perfect molecular orientation represents one of the basic differences between the electrospun fibers and those prepared using the concept of microfibrillar composites [183] - the formation of electrospun

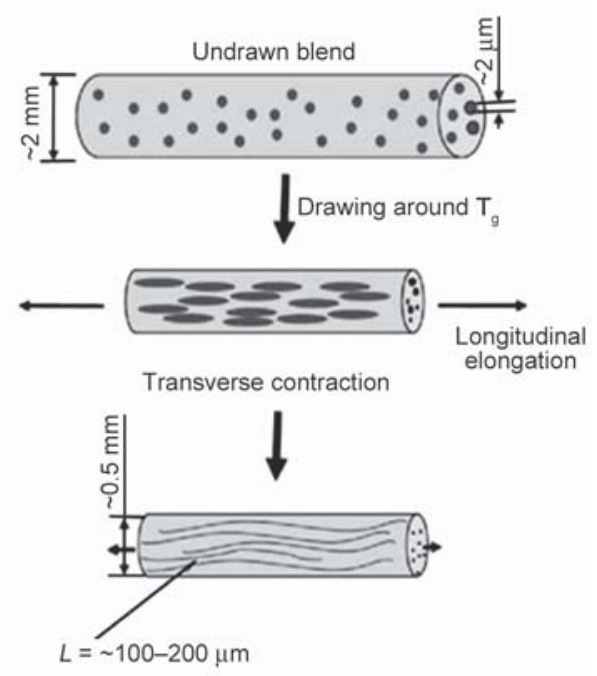

Figure 5. Schematic the microfibrils formation mechanism in polymer blends during cold drawing (transformation of the spherical particles into micro- or nanofibrils via coalescence under transverse contraction) [185].

fibers takes place in polymer solutions or melts where the drawing could hardly result in significant molecular orientation as demonstrated above [165-170].

The considerations about the weak molecular orientation hold also for MFCs prepared similarly but with hot-stretching directly from the melt at a temperature far above both polymers' glass transition temperatures [193-201]. It is well-known that drawing of polymer melts does not induce molecular orientation.

Neat polymer nanofibrils (Figure $7 b$ ) can be easily prepared to apply the MFC concept comprising the steps of melt blending of the two polymers, extrusion, cold drawing and extraction of the matrix component (e.g. [202, 203]. The last step could be performed immediately after the cold drawing or after the compression molding needed for isotropization of the matrix component. The common solvent for removing the matrix polymer is xylene but if the neat nanofibrils are needed for biomedical purposes, for

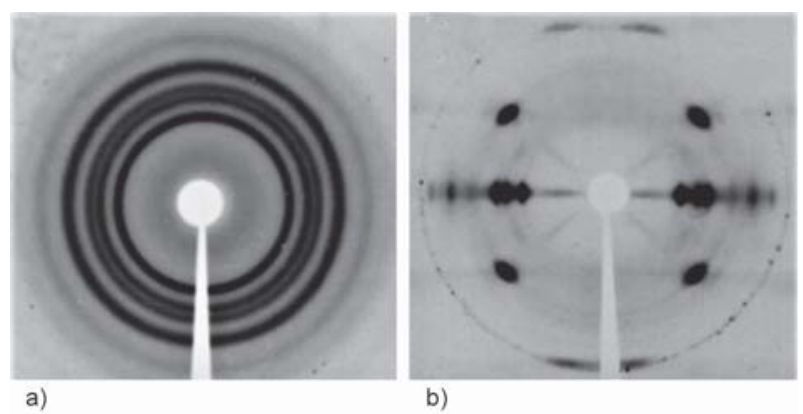

Figure 6. WAXS patterns of PP/PET blend bristle: (a) after extrusion (no drawing) and (b) after extrusion and cold drawing [184]. 


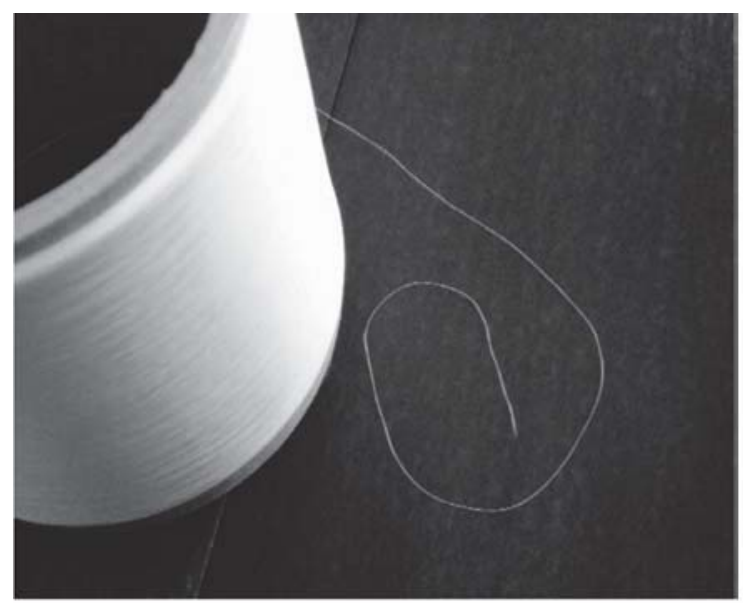

a)

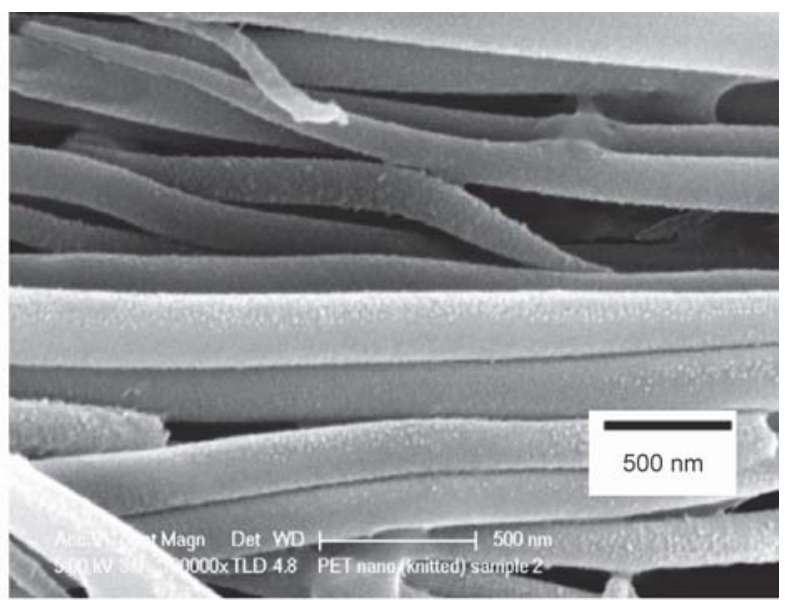

b)

Figure 7. Blend of PP/PET = 70/30 (by wt) subjected to conventional melt spinning: (a) photograph of yarn of filaments with diameters of $30 \mu \mathrm{m}$, (b) SEM micrograph of neat PET nanofibrils isolated from the yarn (a) via removing of PP with boiling xylene using the modified Soxhlet apparatus [206].

example, scaffolds for regenerative medicine, water is the preferred solvent as well as a respective watersoluble polymer as a matrix [204, 205].

\section{The solution of the dispersion problem in the preparation of polymer nanocomposites via the concept of 'converting instead of adding'}

Currently, we do not have reliable tools and/or techniques for proper dispersion of nanomaterials in polymer melts to reach the dispersion degree of single nanoparticles what is the requirement for having true nanocomposites. So long as the respective tools and techniques are missing, for the preparation of such composites, one must use methods free of the dispersion step in the manufacturing process. Besides, the reinforcing component must be fibrous, i.e. for manufacturing of polymer nanocomposites one must use nanofibers characterized by superior mechanical properties.

Do dispersion-free methods for the preparation of polymer nanocomposites exist? There are currently at least two techniques allowing to avoid the dispersion problem in the preparation of polymer nanocomposites. Both result in true nanocomposites, where the nano-size reinforcing component reaches dispersion to single nanoparticles. It is important to note here that these two methods concern the preparation of polymer-polymer nanocomposite only. As demonstrated above [42-132], all attempts to avoid the dispersion step in the preparation of polymer nanocomposites comprising inorganic nanoparticles as reinforcement failed for various reasons.
The two dispersion-free approaches are the essence of the relatively new 'concept of converting instead of adding' [184]. This means that instead of taking the two basic composite components, the matrix and the reinforcement, in their final form and blend them, one takes one component only and during the processing creates the missing second component. Basically, there are two approaches in this respect - creating the originally missing reinforcing, and creating the originally missing matrix:

- creating the reinforcement: starting from a blend of two thermodynamically non-miscible polymers, we can convert the minor blend component into nanofibrils and thus prepare a nanofibrillar polymer-polymer composite (PPC), and

- creating the matrix: if we have neat polymer nanofibrils, by means of thermal treatment close but below the temperature of complete melting, we can produce a small amount of isotropic matrix of the same polymer (playing the role of binder of nanofibrils) and in this way to prepare a nanofibrillar single polymer composite (SPC).

Both techniques are free of the dispersion step and, what is more important, one always observes a perfect distribution of the reinforcing nanomaterial in the polymer matrix, that is, each nanofibril is individually surrounded by the matrix polymer and no aggregation is observed on the scanning electron microscopy micrographs.

The manufacturing process of nanofibrillar PPCs and SPCs is schematically shown in Figure 8. It should be noted that this process could be performed on standard equipment for polymer processing. The two 


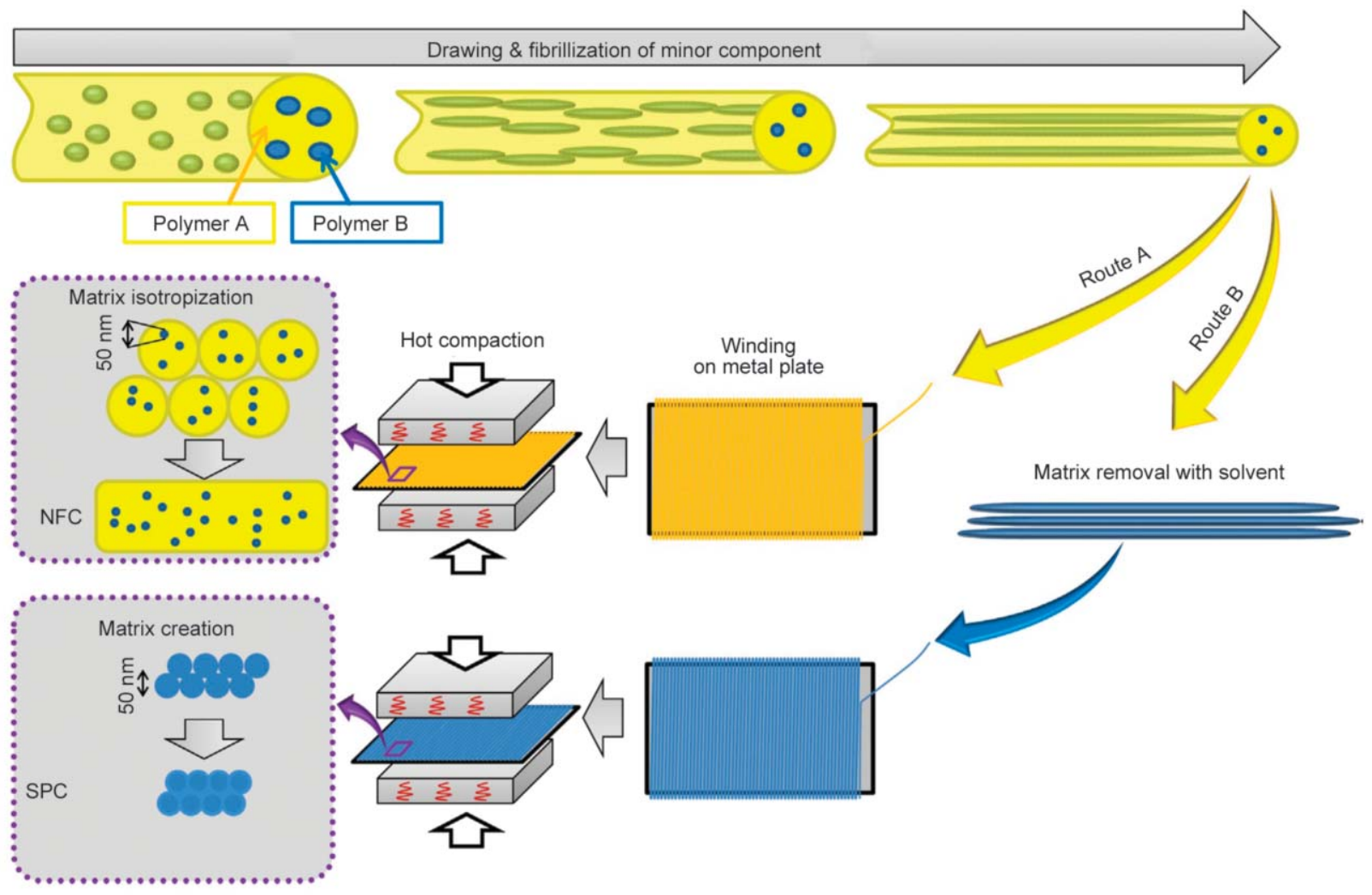

Figure 8. Manufacturing of nanofibrillar composite (NFC), (Route A), and nanofibrillar SPCs, (Route B), via the 'concept of converting instead of adding' [11].

thermodynamically non-miscible polymers in a usual ratio matrix/reinforcement $=70 / 30$ (by wt) are melt blended, extruded and cold drawn. Thereafter, depending on the target, one goes Route A or Route B (Figure 8).

If a nanofibrillar polymer-polymer composite is needed, the drawn bristle is wound on a metal plate and subjected to compression molding at the melting temperature of the matrix polymer $\mathrm{A}$, which must be at least $40^{\circ} \mathrm{C}$ below the melting of the reinforcing polymer B (Figure 8, Route A).

For the preparation of nanofibrillar single polymer composites, one must select Route B (Figure 8), according to which from the drawn bristles must be removed the matrix polymer A using a selective solvent. The rest of nanofibrillar reinforcing bunch of $\mathrm{B}$ must be wound on a metal plate and compressionmolded at a temperature at least $20^{\circ} \mathrm{C}$ below the melting temperature of B (Figure 8, Route B). In this way, due to a partial surface melting, a small amount of isotropic matrix (binder of nanofibrils) is created (Figure 8, Route B). The hot-compaction has been carried out at temperature corresponding to the start of the melting process as shown for poly(vinylidene fluoride) (PVDF) in Figure 9. In many cases, this temperature is by $20^{\circ} \mathrm{C}$ lower than the temperature of complete melting.

Information regarding the sizes of the reinforcing nanofibrils and their distribution in the matrix we can obtain from the SEM analysis. Such results for the two types of nanocomposites under discussion are shown in Figures 10 and 11.

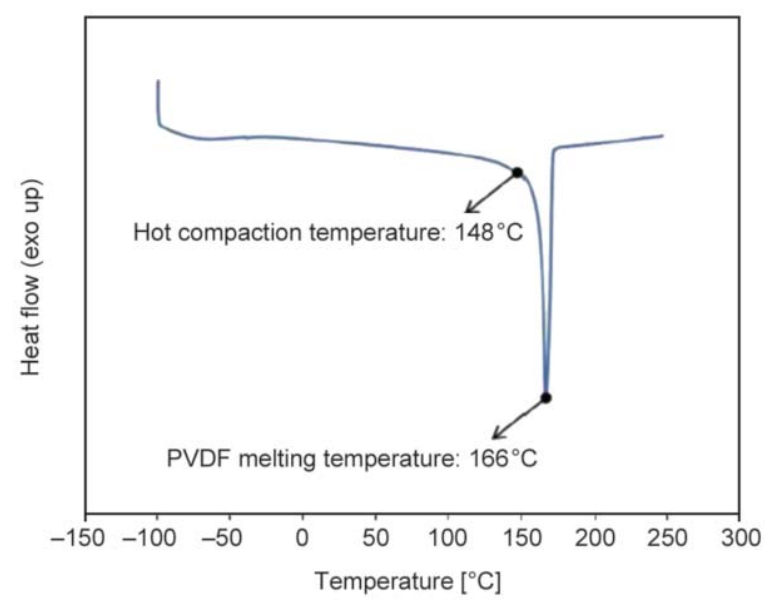

Figure 9. Differential scanning calorimetry curve of PVDF demonstrating the melting interval, the true melting temperature $\left(166^{\circ} \mathrm{C}\right)$ and the selection of the proper hot compaction temperature $\left(148^{\circ} \mathrm{C}\right)$ below enough the true melting temperature [189]. 


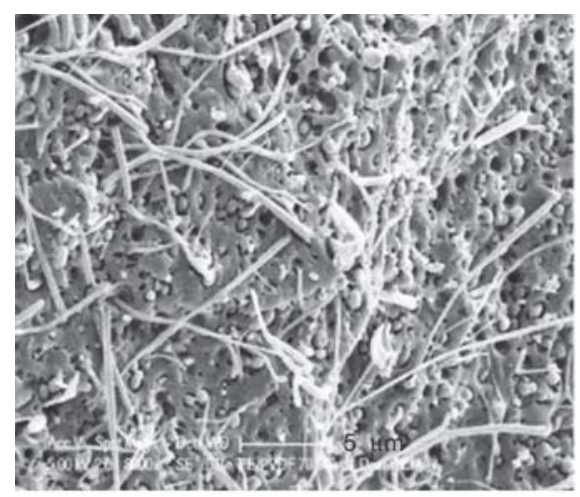

a)

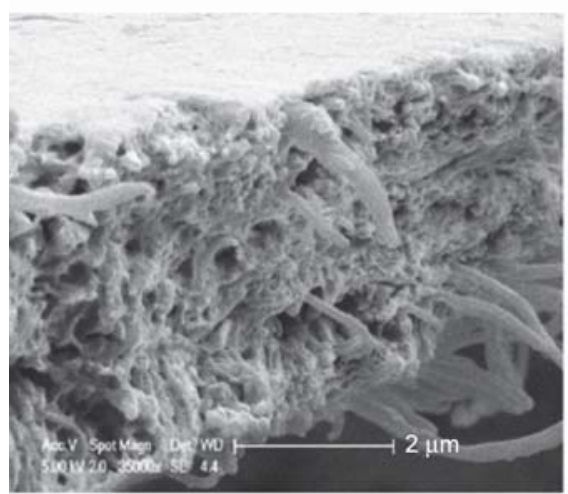

c)

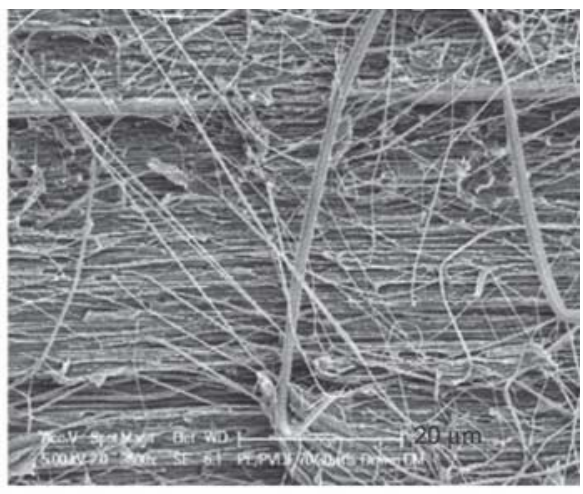

b)

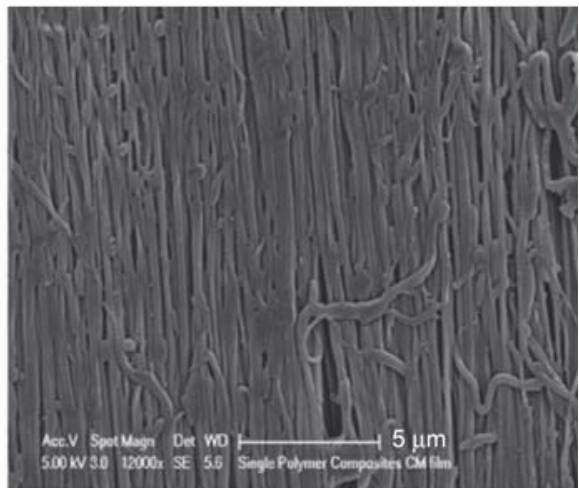

d)

Figure 10. SEM micrographs of polyethylene/poly(vinylidene fluoride) (PE/PVDF = 70/30 by wt) nanofibrillar polymerpolymer composite ( $a$ and $b$ ) and PET nanofibrillar single polymer composite ( $c$ and d): a) and c) represent cryofractures perpendicular to the nanofibril orientation, b) is cryofracture parallel to the nanofibrils orientation, and d) is the surface of the SPC film shown in c) [11].

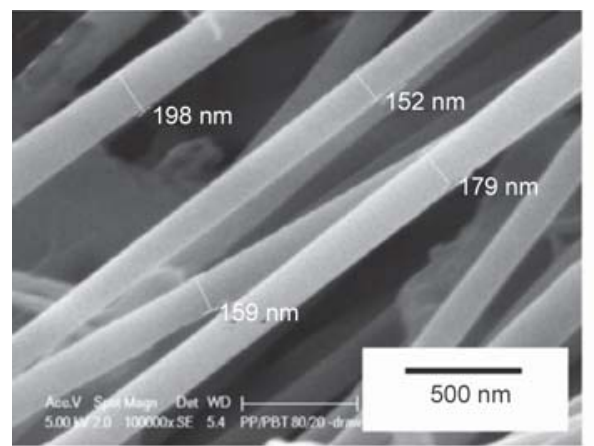

a)

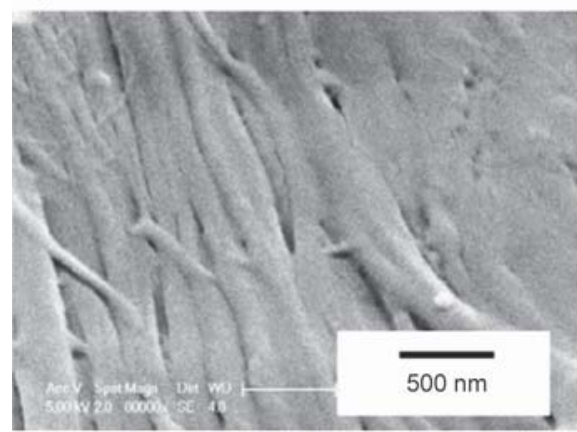

c)

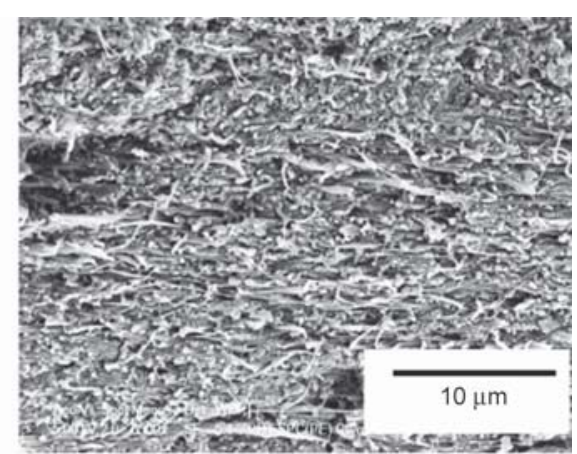

b)

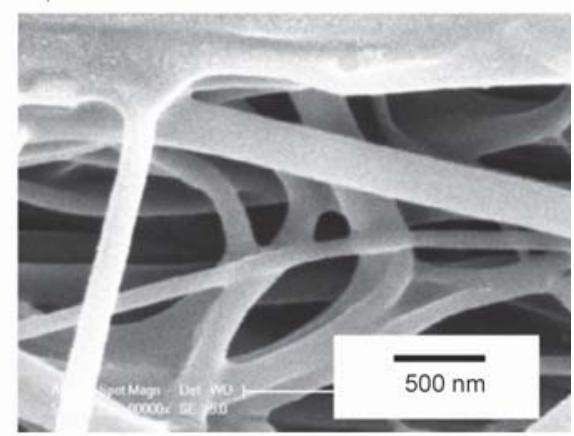

d)

Figure 11. SEM micrographs of (a) PBT nanofibrils isolated from PP/PBT (80/20 by wt) drawn blend and used for preparation of SPC via hot compaction, (b) cryofracture cross-section surface of a nanofibrillar SPC prepared from nanofibrils of (a), (c) the top surface of compression-molded 'film' of PET nanofibrils (as those in Figure 7b), and (d) cryofracture cross-section surface of a nanofibrillar SPC shown in (c), which demonstrates the adhering of nanofibrils as a result of surface pre-melting [184]. 
An even better idea about the preparation of the nanofibrillar SPCs could be obtained from microphotographs displayed in Figure 11 where are shown the starting nanofibrils as well as the structure of the obtained film after compression molding. It is well demonstrated the fact that the thermal treatment of the aligned nanofibrils does not result in complete melting but only in adhering to the contacting nanofibrils (Figure 11d).

The photographs taken from the cryofractures perpendicular to the nanofibrils orientation (Figures 10a and 10c, Figures $11 \mathrm{~b}$ and $11 \mathrm{~d}$ )), as well as from cryofracture parallel to the nanofibrils orientation (Figure 10b) in both types of nanocomposites, the polymer-polymer ones as well as the SPCs, demonstrate rather homogeneous distribution of the reinforcing nanofibrils in the polymer matrix, i.e. practically no aggregates of nanofibrils can be observed. Such a situation is quite different from the case of polymer nanocomposites prepared via the blending of the two starting components as demonstrated in the previous paragraphs.

Coming back to the preparation of these true nanofibrillar polymer composites it should be stressed that the formation of the reinforcing nanofibrils possibly starts during the melt blending and extrusion but takes place mostly during the 'cold' drawing (in the slightly heated chamber - up to the $T_{\mathrm{g}}$-value of the blend component B), as schematically shown in Figure 12.

The basic requirement for the preparation of nanofibrils is again to use blends of thermodynamically

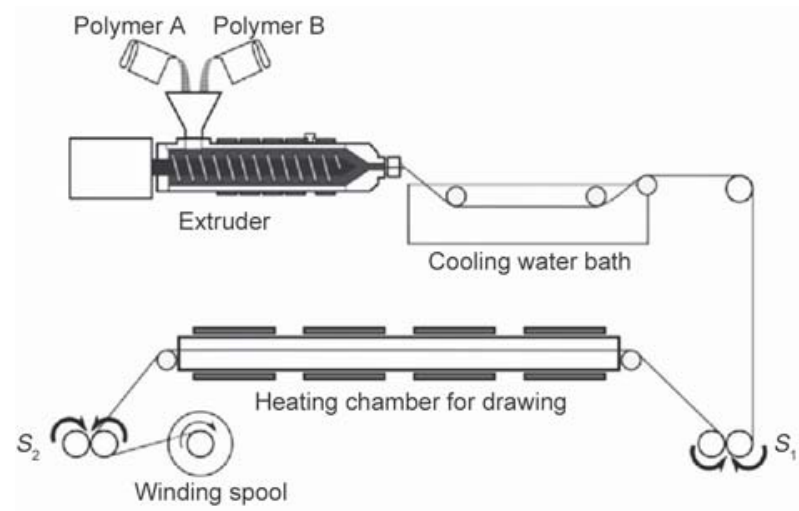

Figure 12. Schematic the setup for the manufacturing process of polymer nanofibrils in polymer blends, used for the preparation of polymer-polymer nanofibrillar composites. It comprises two distinct steps: (i) melt blending and extrusion, and (ii) cold drawing with fibrillation $\left(S_{1}\right.$ and $S_{2}$ are the rotating velocities of the pairs of rolls, where $S_{1}<S_{2}$ ) [11]. non-miscible polymers. In addition to this, there are other three key requirements that must be satisfied, namely: (i) the blended polymers must have sufficient draw ability to allow the formation of reinforcing fibrils to occur, (ii) the two partner polymers must be able to be processed at a single temperature without the onset of degradation in either polymer and (iii) the melting temperature of the reinforcing component must exceed that of the matrix polymer by at least $40^{\circ} \mathrm{C}$, to allow fibril retention during matrix consolidation and isotropization. Once these requirements have been satisfied, the process can be run using standard industrial polymer processing equipment as shown in Figure 12.

\section{Mechanical properties of the true nanofibrillar polymer-polymer and single polymer composites}

Let me remind the readers that the first task of this review article is to try to answer the question of why the polymer nanocomposites prepared via blending the polymer matrix with the reinforcing nanomaterial do not justify the expectations regarding their mechanical performance. Instead of the expected at least ten times higher improvements as compared with the common polymer composites, the reported values of improvements (if any!) are not higher than $30-35 \%$ [4-8].

What about the mechanical performance of the true nanofibrillar polymer-polymer and single polymer composites? In Table 4 are shown the tensile properties of some nanofibrillar polymer-polymer composites prepared according to the concept of converting instead of adding [184]. These properties are compared with those of the neat isotropic matrix polymer prepared in the same way (compression molding). The superior mechanical performance of the nanofibrillar polymer-polymer composites, prepared

Table 4. Improvements in tensile modulus, $E$, and tensile strength, $\sigma$, of nanofibrillar polymer-polymer composites (comparison with an isotropic matrix material, as well as with PP/glass fibers (GF) composite).

\begin{tabular}{|c|l|c|r|r|r|}
\hline$\#$ & Components & $\begin{array}{c}\text { Composition } \\
{[\mathbf{w t} \%]}\end{array}$ & $\begin{array}{c}\boldsymbol{E} \\
{[\%]}\end{array}$ & $\begin{array}{c}\boldsymbol{\sigma} \\
{[\%]}\end{array}$ & Ref. \\
\hline 1. & PP/PET & $80 / 20$ & 50 & 22 & {$[187]$} \\
\hline 2. & LLDPE/PVDF & $70 / 30$ & 165 & 230 & {$[189]$} \\
\hline 3. & PP/PBT & $70 / 30$ & 45 & 190 & {$[191]$} \\
\hline \multicolumn{5}{|c|}{ For comparison } \\
\hline 4. & PP/GF & $80 / 20$ & 100 & 200 & {$[181]$} \\
\hline
\end{tabular}


according to the "concept of converting instead of adding' (Table 4 ) originates from the very high aspect ratio of nanofibrils, their better adhesion to the matrix as compared with their mineral counterparts and mostly because the perfect distribution of nanofibrils in the matrix. Each nanofibril is individually surrounded by matrix material with absolute lacking any aggregates as demonstrated in Figures 10 and 11 and discussed above. These favorable characteristics are the reason for an interesting observation during the tensile testing - the accuracy (error bar) for the polymer-polymer composites (Table 4, samples 1, 2 and 3) represents $5-10 \%$ only of the measured value, while for the PP/GF (Table 4, sample 4) - it is between 50 and $100 \%$ [181]. This observation indicates the high uniformity (in any aspect) as compared with glass fiber composites.

In Table 5 are listed data regarding the reinforcing effect in tensile experiments of the true nanofibrillar (diameter of nanofibrils between 10 and $250 \mathrm{~nm}$ ) SPCs, prepared via one- or two-constituent approaches. The comparison is done with an isotropic film of the same polymer prepared via compression molding with a thickness like that of the composite samples. Considering the differences in the mechanical performance of the SPCs prepared using the one- or two-constituent approach (Table 5, samples 2, 3, 5, 6,7 and 1,4 , respectively) one has to take into account the drastic difference in the structure of the two types of materials. While the one-constituent approach results in a more homogeneous distribution of the reinforcing fibrils in the matrix, the two-constituent approach (Table 5, samples 1 and 4) leads to a typical layered structure comprised of film(s) and

Table 5. Improvement in tensile modulus, $E$, and tensile strength, $\sigma$, of true nanofibrillar SPCs (comparison with isotropic matrix material, i.e. isotropic film of the same polymer).

\begin{tabular}{|c|l|c|c|c|c|}
\hline$\#$ & Polymer & $\begin{array}{c}\text { Constituent } \\
\text { (one/two) }\end{array}$ & $\begin{array}{c}\boldsymbol{E} \\
{[\%]}\end{array}$ & $\begin{array}{c}\boldsymbol{\sigma} \\
{[\%]}\end{array}$ & Ref. \\
\hline 1. & PET & Two & Up to 100 & Up to 140 & {$[190]$} \\
\hline 2. & PVDF & One & 40 & 330 & {$[189]$} \\
\hline 3. & PET & One & $\begin{array}{c}350 \text { (for } \\
E=10.57 \mathrm{GPa})\end{array}$ & 300 & {$[188]$} \\
\hline 4. & PBT & Two & 35 & 5 & {$[191]$} \\
\hline 5. & PBT & One & 31 & 35 & {$[191]$} \\
\hline 6. & LLDPE & One & 112 & 325 & {$[209]$} \\
\hline 7. & PP & One & 70 & 440 & {$[209]$} \\
\hline \multicolumn{7}{|c|}{ For comparison } \\
\hline 8. & PET/GF & Two & Up to $100-150$ & - & {$[206]$} \\
\hline
\end{tabular}

fibers of the same polymer. For example, the PET nanofibrillar SPCs prepared according to the one constituent approach (Table 5, sample 3) are characterized by an average modulus value of $6.85 \mathrm{GPa}$ and a maximum one of $10.57 \mathrm{GPa}$. This value surpasses all previously reported values for SPCs based on PET [212-215] and approaches even the stiffness of the glass fiber reinforced PET composite (with an $E$ modulus of $11 \mathrm{GPa}$ for $40 \mathrm{wt} \%$ glass fibers [207, 208]). Discussing this remarkable mechanical performance of the nanofibrillar single polymer composite based on PET (Table 5, sample 3), whose SEM micrographs are shown in Figures 10c and 10d, we need to comment on another detail. Accounting the fact that the sample consists of PET nanofibrils only (Figures 10c and $10 \mathrm{~d}$ ) and that the mechanical testing has been performed in the fiber axis direction only, one can assume that the obtained values for $E$ and $\sigma$ are characteristic for the single nanofibrils also (or, possibly, even higher for them). As a matter of fact, the $E$-values between 7 and $10 \mathrm{GPa}$ for the PET nanofibrils prepared using concept converting instead of adding are in vicinity of the $E$-value for the melt-spun PET fibers (Table 3, sample 13) of $15 \mathrm{GPa}$. This similarity demonstrates that in the manufacturing of these two types of fibers participates the step drawing, which creates a strong molecular orientation leading to superior mechanical performance. Such a step is missing in the manufacturing of electrospun fibers as it follows from their mechanical properties $E$-value of around $1 \mathrm{GPa}$ for single PA-66 and PA-6 nanofibers (Table 3, samples 4, 5 and 7).

Quite similar is the situation with the tensile strength where improvements of about $300 \%$ are achieved in contrast to all other SPCs found in the literature [209215], including the PET/glass fiber composite, for which the improvement is 100-150\% [206]. The tensile strength of the same type SPC based on PVDF, LLDPE and PP (Table 3, samples 2, 6 and 7) also are very impressive.

Single polymer composites have an inherent advantage compared to all other polymer composites regarding the adhesion quality between matrix and reinforcement, which has a fundamental role in the formation of mechanical properties. Strong interfacial interaction between reinforcing particle and polymer matrix is crucial to achieving a desirable level of reinforcement in polymer composites [216, 217]. Otherwise, insufficient interfacial interactions cause weak load transfer from the polymer matrix to 
the reinforcement which promotes significant stress concentration at the interface region deteriorating the performance of polymer composites [217]. Basically, the influence of interface region and the degree of interfacial interaction would be much pronounced in polymer nanocomposites, because of the extremely large specific surface area of nanoparticles compared with conventional microparticles. However, to take the full advantage of such a large specific surface area of nanoparticles in polymer nanocomposites, the nanoparticles should be dispersed in the polymer matrix in nanoscale which should normally be achieved during the mixing/dispersion step of nanocomposite fabrication, as discussed in preceding sections. The interfacial adhesion in polymer/ nanoparticle composites is basically developed via the interaction of polymer macromolecules with the surface of nanoparticles through physical interaction, e.g. Van der Waals forces, or chemical bonding such as covalent bonding. Normally, chemical bonding provides strong interfacial adhesion which is often achieved with chemically surface-modified nanoparticles. Nevertheless, interfacial adhesion alters significantly the dynamics and conformation of macromolecules [218] or promotes the crystallinity of macromolecules $[219,220]$ in the vicinity of the outer surface of nanoparticles leading to distinct layer in the interface region, referred to as interphase, with transitional properties from the nanoparticle properties at the interface to the polymer matrix itself [221]. The thickness of the interphase layer is often in the order of the radius of gyration of macromolecules. It seems interesting to note here that the problem of adhesion quality in the case of SPCs does not exist since the two basic composite components, the matrix and the reinforcement, are of the same chemical composition. Nevertheless, even higher values for the mechanical properties are achievable if additional special care will be taken for further improvement of the adhesion quality between the matrix and reinforcement via establishing chemical bonds between them. What is more, the chemical interactions (the additional condensation and trans-reactions in case of condensation polymers) could be further enhanced using trans-reaction catalysts (e.g. $\mathrm{Sb}_{2} \mathrm{O}_{3}$ ) as recently demonstrated for Nylon 6 (PA-6) [222]. While the improvement of the tensile modulus is almost the same for the cases without and with catalyst, the tensile strength of the single polymer composites as compared with the isotropic PA- 6 improves by $300-400 \%$ (depending on the moisture content) for the samples without catalyst and by $500-650 \%$ when catalyst is added [222].

The improvements in the tensile mechanical properties of all SPCs so far studied [209-215] and particularly the superior mechanical properties of the new nanofibrillar SPCs prepared by hot compaction using only one constituent are evident (Table 5). What could be the reason for this impressive mechanical performance? There are at least four reasons: (i) in the current SPCs the reinforcing nanofibrillar constituent dominates strongly and has much better mechanical properties when compared with the isotropic matrix of the same polymer, (ii) perfect adhesion between matrix and reinforcement because they have the same chemical composition, (iii) better orientation of the macromolecules in nanofibrils as compared to that in microfibrils and textile filaments of the same polymer, and (iv) in the test specimen of SPCs the nanofibrils are uniaxially aligned and the testing has been performed so far in the drawing direction only.

To the factors contributing to the superior mechanical properties of the nanofibrillar SPCs (Table 5) and the nanofibrillar polymer-polymer composites also belongs the fact that they are manufactured not via blending the matrix and reinforcement but using a technique which excludes the dispersion step in the processing. This technique results in a perfect distribution of nanofibrils in the matrix where each nanofibril is individually surrounded by the matrix, that is, one deals with true polymer nanocomposites.

In addition to the perfect distribution of the reinforcement in the matrix, one has to mention that the reinforcing component is distinguished by extremely high aspect ratio values since it represents nanofibers (diameters between 50 and $250 \mathrm{~nm}$ ). What is more, these nanofibers demonstrate excellent mechanical properties contrasting, for example, the elctrospun nanofibers (Table 3 ).

Summarizing, it should be noted that there is no surprise in these superior mechanical properties (improvements of 200,300 , or $400 \%$ !) of the nanofibrillar polymer-polymer and the nanofibrillar single polymer composites prepared via the concept of converting instead of adding because: (i) they are true nanocomposites where (ii) the reinforcing agent is of high aspect ratio, and (iii) the adhesion quality (particularly for the SPCs) is perfect. For such systems, the expectations about a ten-fold increase of 
mechanical properties are justified contrasting the polymer nanocomposites prepared via the blending of the polymer with the inorganic nanomaterials, where the improvements of mechanical properties are up to $30-35 \%$ ! [4-8].

\section{Conclusions and outlook}

Concluding, it should be mentioned that nowadays, there are enough indications (e.g. [4-8]) that the concept of polymer nanocomposites does not meet the expectations - a drastic difference between the theoretically derived and the experimentally obtained results regarding the mechanical properties of these materials is observed. Among the many reasons for this unexpected situation, the most important seems to be the poor dispersion, in other words, we hardly deal with true nanocomposites. This is because in the composites prepared via the blending of polymer matrix with the reinforcing nano-size material the reinforcing elements are not the single nanoparticles but their aggregates with sizes in the micrometer range. The reason for this situation is the current lack of reliable techniques for proper dispersion of nanomaterial aggregates into the polymer matrix [9] and so long such techniques are missing we must avoid the dispersion step in the preparation of true polymer nanocomposites as the 'concept of converting instead of adding' does. The essence of this concept is in not taking the matrix and reinforcement in their final form but creating one of them during composite processing [181-191, 202-205, 209, 213, 222-224]. In this way, avoiding the dispersion step and achieving a perfect distribution of the nano-size reinforcement, one obtains polymer nanocomposites with excellent mechanical performance (up to $300-400 \%$ improvement in tensile strength and modulus) i.e. up to 10 times higher than polymer nanocomposites prepared via the blending of matrix and reinforcement.

It must be stressed here that the conclusion regarding the type of polymer composites prepared via blending the polymer and the nano reinforcement is based on publications dealing mostly with inorganic nanomaterials. The suggested approach for solving the dispersion problems would be beneficial in terms of especially mechanical performance and only applicable to polymer-polymer systems. If the aim is not mechanical but, say, electrical or magnetic performance (via using inorganic nanoparticles), then the offered technique would be not applicable.
The properties of these polymer nanocomposites can be further improved attacking the rest of their drawbacks as poor interfacial load transfer, process-related deficiencies, poor alignment, poor load transfer to the interior of filler bundles. Besides, the author believes that the efforts of researchers must continue in this direction [12], instead of preparation of 'new' polymer nanocomposites via blending of nano-size materials with polymers and finally getting materials with poor improvement (if any) in their mechanical performance. Alternatively, one could make use of the presence of the nano-size filler having a specific effect on polymer behavior as the case is with polypropylene comprising surface-treated nano-silica.

\section{Acknowledgements}

The author would like to thank Dr VB Mohan for his valuable technical help during the preparation of the manuscript and A/Prof. CJR Verbeek for careful reading and suggesting improvements of the manuscript, as well as Revs P. and S. Stewart for the polishing of the revised version of the contribution. Thanks go also to the Publishers Elsevier, Royal Society of Chemistry and Taylor \& Francis Inc. for adapting figures with the respective text from their publications (refs. $[11,26,27]$, and [184] of Elsevier, ref. [142] of Royal Society of Chemistry as well as ref. [185] of Taylor \& Francis Inc.). Appreciations are also due for their warm hospitality to the Centre for Advanced Composite Materials as well as to the Department of Mechanical Engineering of The University of Auckland, where this project was completed.

\section{References}

[1] Buzea C., Pacheco I. I., Robbie K.: Nanomaterials and nanoparticles: Sources and toxicity. Biointerphases, 2, MR17-MR71 (2007). https://doi.org/10.1116/1.2815690

[2] Nanomaterials, European Commission, https://ec. europa.eu/environment/chemicals/nanotech/faq/definition en.htm.

[3] Iijima S.: Helical microtubules of graphitic carbon. Nature, 354, 56-58 (1991). https://doi.org/10.1038/354056a0

[4] Schaefer D. W., Justice R. S.: How nano are nanocomposites? Macromolecules, 40, 8501-8517 (2007). https://doi.org/10.1021/ma070356w

[5] Friedrich K., Fakirov S., Zhang Z.: Polymer composites: From nano- to macro-scale. Springer, New York (2005).

[6] Bousmina M.: Fundamental insight into polymer nanocomposites. in 'Abstracts of $21^{\text {st }}$ Annual Meeting of Polymer Processing Society (PPS 21), Leipzig, Germany' 219-219 (2005). 
[7] Zhang M. Q., Rong M. Z., Friedrich K.: Application of non-layered nanoparticles in polymer modification. in 'Polymer composites' (eds.: Friedrich K., Fakirov S., Zhang Z.) Springer Science and Business Media, New York 25-44 (2005).

[8] Kumar S. K., Benicewicz B. C., Vaia R. A., Winey K. I.: $50^{\text {th }}$ anniversary perspective: Are polymer nanocomposites practical for applications? Macromolecules, 50, 714-731 (2017).

https://doi.org/10.1021/acs.macromol.6b02330

[9] Greiner A., Wendorff J. H.: Electrospinning: A fascinating method for the preparation of ultrathin fibers. Angewandte Chemie International Edition, 46, 56705703 (2007).

https://doi.org/10.1002/anie.200604646

[10] Chung D. D. L.: Comparison of submicron-diameter carbon filaments and conventional carbon fibers as fillers in composite materials. Carbon, 39, 1119-1125 (2001)

https://doi.org/10.1016/S0008-6223(00)00314-6

[11] Fakirov S.: Nanofibrillar polymer-polymer and single polymer composites via the "converting instead of adding' concept - examples of true polymer nanocomposite. Advanced Industrial and Engineering Polymer Research, 1, 40-47 (2018).

https://doi.org/10.1016/j.aiepr.2018.02.001

[12] Fakirov S.: Polymer nanocomposites: Problems, preparation, mechanical properties. Advanced Materials Letters, 9, 400-405 (2018).

https://doi.org/10.5185/amlett.2018.1850

[13] Zare Y.: Study of nanoparticles aggregation/agglomeration in polymer particulate nanocomposites by mechanical properties. Composites Part A: Applied Science and Manufacturing, 84, 158-164 (2016). https://doi.org/10.1016/j.compositesa.2016.01.020

[14] Islam M. S., Masoodi R., Rostami H.: The effect of nanoparticles percentage on mechanical behavior of silica-epoxy nanocomposites. Journal of Nanoscience, 2013, 275037/1-275037/10 (2013). https://doi.org/10.1155/2013/275037

[15] Liu J., Gao Y., Cao D., Zhang L., Guo Z.: Nanoparticle dispersion and aggregation in polymer nanocomposites: Insights from molecular dynamics simulation. Langmuir, 27, 7926-7933 (2011).

https://doi.org/10.1021/la201073m

[16] Hou G., Tao W., Liu J., Gao Y., Zhang L., Li Y.: Tailoring the dispersion of nanoparticles and the mechanical behavior of polymer nanocomposites by designing the chain architecture. Physical Chemistry Chemical Physics, 19, 32024-32037 (2017). https://doi.org/10.1039/c7cp06199d

[17] Wang H., Xu P., Zhong W., Shen L., Du Q.: Transparent poly(methyl methacrylate)/silica/zirconia nanocomposites with excellent thermal stabilities. Polymer Degradation and Stability, 87, 319-327 (2005). https://doi.org/10.1016/j.polymdegradstab.2004.08.015
[18] Anžlovar A., Orel Z. C., Žigon M.: Sub micrometer and nano $\mathrm{ZnO}$ as filler in PMMA materials. Materiali in Tehnologije, 45, 269-274 (2011).

[19] Hu Y., Zhou S., Wu L.: Surface mechanical properties of transparent poly(methyl methacrylate)/zirconia nanocomposites prepared by in situ bulk polymerization. Polymer, 50, 3609-3616 (2009).

https://doi.org/10.1016/j.polymer.2009.03.028

[20] Zhang Y., Wang X., Liu Y., Song S., Liu D.: Highly transparent bulk PMMA/ZnO nanocomposites with bright visible luminescence and efficient UV-shielding capability. Journal of Materials Chemistry, 22, 1197111977 (2012). https://doi.org/10.1039/C2JM30672G

[21] Clayton L. M., Sikder A. K., Kumar A., Cinke M., Meyyappan M., Gerasimov T. G., Harmon J. P.: Transparent poly(methyl methacrylate)/single-walled carbon nanotube (PMMA/SWNT) composite films with increased dielectric constants. Advanced Functional Materials, 15, 101-106 (2005).

https://doi.org/10.1002/adfm.200305106

[22] Barnakov Y. A., Scott B., Golub V., Kelly L., Reddy V., Stokes K.: Spectral dependence of Faraday rotation in magnetite-polymer nanocomposites. Journal of Physics and Chemistry of Solids, 65, 1005-1010 (2004).

https://doi.org/10.1016/j.jpcs.2003.10.070

[23] Peluso A., Pagliarulo V., Carotenuto G., Pepe G. P., Davino D., Visone C., Longo A., Capezzuto F.: Synthesis and characterization of polymer embedded Iron oxide nanocomposites. Microwave and Optical Technology Letters, 51, 2774-2777 (2009).

https://doi.org/10.1002/mop.24733

[24] Parlak O., Demir M. M.: Anomalous transmittance of polystyrene-ceria nanocomposites at high particle loadings. Journal of Materials Chemistry C, 1, 290298 (2013).

https://doi.org/10.1039/C2TC00084A

[25] Huang J., Yang Y., Xue S., Yang B., Liu S., Shen J.: Photoluminescence and electroluminescence of $\mathrm{ZnS}: \mathrm{Cu}$ nanocrystals in polymeric networks. Applied Physics Letters, 70, 2335-2337 (1997).

https://doi.org/10.1063/1.118866

[26] Hakimelahi H. R., Hu L., Rupp B. B., Coleman M. R.: Synthesis and characterization of transparent alumina reinforced polycarbonate nanocomposite. Polymer, 51, 2494-2502 (2010).

https://doi.org/10.1016/j.polymer.2010.04.023

[27] Chandra A., Turng L-S., Li K., Huang H-X.: Fracture behavior and optical properties of melt compounded semi-transparent polycarbonate (PC)/alumina nanocomposites. Composites Part A: Applied Science and Manufacturing, 42, 1903-1909 (2011).

https://doi.org/10.1016/j.compositesa.2011.08.015

[28] Sarwar M. I., Zulfiqar S., Ahmad Z.: Investigating the property profile of polyamide-alumina nanocomposite materials. Scripta Materialia, 60, 988-991 (2009). https://doi.org/10.1016/j.scriptamat.2009.02.034 
[29] Loste J., Lopez-Cuesta J-M., Billon L., Garay H., Save M.: Transparent polymer nanocomposites: An overview on their synthesis and advanced properties. Progress in Polymer Science, 89, 133-158 (2019). https://doi.org/10.1016/j.progpolymsci.2018.10.003

[30] Wang W. S., Liang C. K., Chen Y. C., Su Y. L., Tsai T. Y., Chen-Yang Y. W.: Transparent and flame retardant PMMA/clay nanocomposites prepared with dual modified organoclay. Polymers for Advanced Technologies, 23, 625-631 (2012).

https://doi.org/10.1002/pat.1936

[31] Hu Y., Gu G., Zhou S., Wu L.: Preparation and properties of transparent $\mathrm{PMMA} / \mathrm{ZrO}_{2}$ nanocomposites using 2-hydroxyethyl methacrylate as a coupling agent. Polymer, 52, 122-129 (2011). https://doi.org/10.1016/j.polymer.2010.11.020

[32] Guan C., Lü C., Cheng Y., Song S., Yang B.: A facile one-pot route to transparent polymer nanocomposites with high $\mathrm{ZnS}$ nanophase contents via in situ bulk polymerization. Journal of Materials Chemistry, 19, 617-621 (2009).

https://doi.org/10.1039/B818876A

[33] Kubiak J. M., Yan J., Pietrasik J., Matyjaszewski K.: Toughening PMMA with fillers containing polymer brushes synthesized via atom transfer radical polymerization (ATRP). Polymer, 117, 48-53 (2017). https://doi.org/10.1016/j.polymer.2017.04.012

[34] Matsuno R., Otsuka H., Takahara A.: Polystyrenegrafted titanium oxidenanoparticles prepared through surface-initiated nitroxide-mediated radical polymerization and their application to polymer hybrid thin films. Soft Matter, 2, 415-421 (2006). https://doi.org/10.1039/B601197G

[35] Mallakpour S., Barati A.: Efficient preparation of hybrid nanocomposite coatings based on poly(vinyl alcohol) and silane coupling agent modified $\mathrm{TiO}_{2}$ nanoparticles. Progress in Organic Coatings, 71, 391-398 (2011). https://doi.org/10.1016/j.porgcoat.2011.04.010

[36] Kim S., Wilkie C. A.: Transparent and flame retardant PMMA nanocomposites. Polymers for Advanced Technologies, 19, 496-506 (2008).

https://doi.org/10.1002/pat.1089

[37] Jeeju P. P., Sajimol A. M., Sreevalsa V. G., Varma S. J., Jayalekshmi S.: Size-dependent optical properties of transparent, spin-coated polystyrene/ZnO nanocomposite films. Polymer International, 60, 1263-1268 (2011). https://doi.org/10.1002/pi.3073

[38] Parlak O., Demir M. M.: Toward transparent nanocomposites based on polystyrene matrix and PMMA-grafted $\mathrm{CeO}_{2}$ nanoparticles. ACS Applied Materials and Interfaces, 3, 4306-4314 (2011).

https://doi.org/10.1021/am200983h

[39] Bodurov I., Yovcheva T., Sainov S.: PMMA films refractive index modulation via $\mathrm{TiO}_{2}$ nanoparticle inclusions and corona poling. Colloid and Polymer Science, 292, 3045-3048 (2014).

https://doi.org/10.1007/s00396-014-3373-y
[40] Tan M. C., Patil S. D., Riman R. E.: Transparent infrared-emitting $\mathrm{CeF}_{3}: \mathrm{Yb}-\mathrm{Er}$ polymer nanocomposites for optical applications. ACS Applied Materials and Interfaces, 2, 1884-1891 (2010).

https://doi.org/10.1021/am100228j

[41] van de Hulst H.: Light scattering by small particles. Wiley, New York (1957).

[42] Bae S. B., Kim C. K., Kim K., Chung I. J.: The effect of organic modifiers with different chain lengths on the dispersion of clay layers in HTPB (hydroxyl terminated polybutadiene). European Polymer Journal, 44, 3385-3392 (2008).

https://doi.org/10.1016/j.eurpolymj.2008.07.012

[43] Chandra A., Turng L-S., Gopalan P., Rowell R. M., Gong S.: Study of utilizing thin polymer surface coating on the nanoparticles for melt compounding of polycarbonate/alumina nanocomposites and their optical properties. Composites Science and Technology, 68, 768-776 (2008).

https://doi.org/10.1016/j.compscitech.2007.08.027

[44] Chatterjee A.: Properties improvement of PMMA using nano $\mathrm{TiO}_{2}$. Journal of Applied Polymer Science, 118, 2890-2897 (2010).

https://doi.org/10.1002/app.32567

[45] de Melo C., Garcia P. S., Grossmann M. V. E., Yamashita F., Dall'Antônia L. H., Mali S.: Properties of extruded xanthan-starch-clay nanocomposite films. Brazilian Archives of Biology and Technology, 54, 1223-1333 (2011). https://doi.org/10.1590/S1516-89132011000600019

[46] Durmus A., Ercan N., Soyubol G., Kasgöz A., Aydin I.: Effects of compatibilizer structure on the clay dispersion and barrier properties of polyethylene/clay nanocomposite films. Academic Journal of Manufacturing Engineering, 8, 49-54 (2010).

[47] Espejo C., Arribas A., Monzó F., Díez P. P.: Nanocomposite films with enhanced radiometric properties for greenhouse covering applications. Journal of Plastic Film and Sheeting, 28, 336-350 (2012). https://doi.org/10.1177/8756087912439058

[48] Farhoodi M., Dadashi S., Mousavi S. M. A., SotudehGharebagh R., Emam-Djomeh Z., Oromiehie A., Hemmati F.: Influence of $\mathrm{TiO}_{2}$ nanoparticle filler on the properties of PET and PLA nanocomposites. Polymer Korea, 36, 745-755 (2012). https://doi.org/10.7317/pk.2012.36.6.745

[49] Haase A., Hesse P., Brommer L., Jacobs O., Abetz C., Handge U. A., Boschetti-de-Fierro A., Abetz V.: Modification of polycarbonate and glycol modified poly (ethylene terephthalate) by addition of silica-nanoparticles grafted with san copolymer using 'classical' and arget ATRP. Macromolecular Materials and Engineering, 298, 292-302 (2013).

https://doi.org/10.1002/mame.201200041 
[50] Hong S-I., Rhim J-W.: Preparation and properties of melt-intercalated linear low density polyethylene/clay nanocomposite films prepared by blow extrusion. LWT-Food Science and Technology, 48, 43-51 (2012). https://doi.org/10.1016/j.lwt.2012.03.009

[51] Inceoglu F., Menceloglu Y. Z.: Transparent low-density polyethylene/starch nanocomposite films. Journal of Applied Polymer Science, 129, 1907-1914 (2013). https://doi.org/10.1002/app.38811

[52] Lee K. M., Han C. D.: Effect of hydrogen bonding on the rheology of polycarbonate/organoclay nanocomposites. Polymer, 44, 4573-4588 (2003).

https://doi.org/10.1016/S0032-3861(03)00444-0

[53] Lerari D., Peeterbroeck S., Benali S., Benaboura A., Dubois P.: Use of a new natural clay to produce poly (methyl methacrylate)-based nanocomposites. Polymer International, 59, 71-77 (2010). https://doi.org/10.1002/pi.2691

[54] Liaw J. H., Hsueh T. Y., Tan T-S., Wang Y., Chiao S-M.: Twin-screw compounding of poly(methyl methacrylate)/clay nanocomposites: Effects of compounding temperature and matrix molecular weight. Polymer International, 56, 1045-1052 (2007).

https://doi.org/10.1002/pi.2241

[55] Niknezhad S., Isayev A. I.: Online ultrasonic film casting of LLDPE and LLDPE/clay nanocomposites. Journal of Applied Polymer Science, 129, 263-275 (2013). https://doi.org/10.1002/app.38725

[56] Romero-Guzmán M. E., Romo-Uribe A., Ovalle-García E., Olayo R., Cruz-Ramos C. A.: Microstructure and dynamic mechanical analysis of extruded layered silicate PVC nanocomposites. Polymers for Advanced Technologies, 19, 1168-1176 (2008).

https://doi.org/10.1002/pat.1098

[57] Singhal A., Skandan G.: Engineered nanomaterial hard coatings on metal and polymer substrates. in 'Surface engineering: Science and technology II’ (eds.: Kumar A., Chung Y-W., Moore J. J., Doll G. L., Yatsui K., Misra D. S.) Wiley, New York, 69-78 (2002). https://doi.org/10.1002/9781118788325.ch8

[58] Strange M., Plackett D., Kaasgaard M., Krebs F. C.: Biodegradable polymer solar cells. Solar Energy Materials and Solar Cells, 92, 805-813 (2008). https://doi.org/10.1016/j.solmat.2008.02.002

[59] Yoon P., Hunter D. L., Paul D. R.: Polycarbonate nanocomposites. Part 1. Effect of organoclay structure on morphology and properties. Polymer, 44, 5323-5339 (2003). https://doi.org/10.1016/S0032-3861(03)00528-7

[60] Zeng X-F., Li X., Tao X., Shen Z-G., Chen J-F.: Fabrication of highly transparent $\mathrm{ZnO} / \mathrm{PVB}$ nanocomposite films with novel UV-shielding properties. in 'The $3^{\text {rd }}$ International Nanoelectronics Conference (INEC), Hong Kong, China' 777-778 (2010). https://doi.org/10.1109/INEC.2010.5424473
[61] Zheng H., Zhang Y., Peng Z., Zhang Y.: Preparation and properties of semi-transparent EPDM/montmorillonite nanocomposites. Polymers and Polymer Composites, 13, 53-60 (2005). https://doi.org/10.1177/096739110501300104

[62] Chae D. W., Kim B. C.: Characterization on polystyrene/zinc oxide nanocomposites prepared from solution mixing. Polymers for Advanced Technologies, 16, 846-850 (2005). https://doi.org/10.1002/pat.673

[63] Demir M. M., Wegner G.: Challenges in the preparation of optical polymer composites with nanosized pigment particles: A review on recent efforts. Macromolecular Materials and Engineering, 297, 838-863 (2012). https://doi.org/10.1002/mame.201200089

[64] Hsiao S-H., Liou G-S., Chang L-M.: Synthesis and properties of organosoluble polyimide/clay hybrids. Journal of Applied Polymer Science, 80, 2067-2072 (2001). https://doi.org/10.1002/app.1306

[65] Mallakpour S., Dinari M.: Nanocomposites of poly (vinyl alcohol) reinforced with chemically modified $\mathrm{AL}_{2} \mathrm{O}_{3}$ : Synthesis and characterization. Journal of Macromolecular Science Part B: Physics, 52, 16511661 (2013).

https://doi.org/10.1080/00222348.2013.789349

[66] van Zyl W. E., García M., Schrauwen B. A., Kooi B. J., De Hosson J. T. M., Verweij H.: Hybrid polyamide/silica nanocomposites: Synthesis and mechanical testing. Macromolecular Materials and Engineering, 287, 106110 (2002).

https://doi.org/10.1002/14392054(20020201)287:2<106::AID-MAME106>3.0.CO;2-2

[67] Althues H., Simon P., Philipp F., Kaskel S.: Integration of zinc oxide nanoparticles into transparent poly(butanediolmonoacrylate) via photopolymerisation. Journal of Nanoscience and Nanotechnology, 6, 409-413 (2006). https://doi.org/10.1166/jnn.2006.917

[68] Chau J. L. H., Lin Y-M., Li A-K., Su W-F., Chang K-S., Hsu S. L-C., Li T-L.: Transparent high refractive index nanocomposite thin films. Materials Letters, 61, 29082910 (2007). https://doi.org/10.1016/j.matlet.2007.01.088

[69] Cheema T. A., Lichtner A., Weichert C., Böl M., Garnweitner G.: Fabrication of transparent polymermatrix nanocomposites with enhanced mechanical properties from chemically modified $\mathrm{ZrO}_{2}$ nanoparticles. Journal of Materials Science, 47, 2665-2674 (2012). https://doi.org/10.1007/s10853-011-6092-5

[70] Cheng P-S., Zeng K-M., Chen J-H.: Preparation and characterization of transparent and UV-shielding epoxy/ Sr-494/APTMS/ZnO nanocomposites with high heat resistance and anti-static properties. Journal of the Chinese Chemical Society, 61, 320-328 (2014). https://doi.org/10.1002/jccs.201300477 
[71] Evora V. M. F., Shukla A.: Fabrication, characterization, and dynamic behavior of polyester $/ \mathrm{TiO}_{2}$ nanocomposites. Materials Science and Engineering: A, 361, 358-366 (2003). https://doi.org/10.1016/S0921-5093(03)00536-7

[72] Jlassi K., Chandran S., Mičušik M., Benna-Zayani M., Yagci Y., Thomas S., Chehimi M. M.: Poly(glycidyl methacrylate)-grafted clay nanofiller for highly transparent and mechanically robust epoxy composites. European Polymer Journal, 72, 89-101 (2015). https://doi.org/10.1016/j.eurpolymj.2015.09.004

[73] Li Y., Tao P., Viswanath A., Benicewicz B. C., Schadler L. S.: Bimodal surface ligand engineering: The key to tunable nanocomposites. Langmuir, 29, 1211-1220 (2012). https://doi.org/10.1021/la3036192

[74] Li Y-Q., Fu S-Y., Mai Y-W.: Preparation and characterization of transparent $\mathrm{ZnO} /$ epoxy nanocomposites with high-UV shielding efficiency. Polymer, 47, 2127 2132 (2006).

https://doi.org/10.1016/j.polymer.2006.01.071

[75] Li Y-Q., Yang Y., Fu S-Y.: Photo-stabilization properties of transparent inorganic UV-filter/epoxy nanocomposites. Composites Science and Technology, 67, 34653471 (2007).

https://doi.org/10.1016/j.compscitech.2007.03.010

[76] Li Y-Q., Yang Y., Fu S-Y., Yi X-Y., Wang L-C., Chen H-D.: Transparent and light-emitting epoxy super-nanocomposites containing $\mathrm{ZnO}-\mathrm{QDs} / \mathrm{SiO}_{2}$ nanocomposite particles as encapsulating materials for solid-state lighting. The Journal of Physical Chemistry C, 112, 1861618622 (2008). https://doi.org/10.1021/jp8050609

[77] Luo Y-S., Yang J-P., Dai X-J., Yang Y., Fu S-Y.: Preparation and optical properties of novel transparent Aldoped-ZnO/epoxy nanocomposites. The Journal of Physical Chemistry C, 113, 9406-9411 (2009). https://doi.org/10.1021/jp901501z

[78] Sunkara H. B., Jethmalani J. M., Ford W. T.: Solidification of colloidal crystals of silica. in 'Hybrid organic-inorganic composites' (eds.: Mark J. E., Lee C. Y-C., Bianconi P. A.) ACS Publications, Washington, Vol 585, 181-191 (1995).

https://doi.org/10.1021/bk-1995-0585.ch014

[79] Suzuki N., Zakaria M. B., Chiang Y-D., Wu K. C-W., Yamauchi Y.: Thermally stable polymer composites with improved transparency by using colloidal mesoporous silica nanoparticles as inorganic fillers. Physical Chemistry Chemical Physics, 14, 7427-7432 (2012). https://doi.org/10.1039/C2CP40356K

[80] Tsai C-M., Hsu S-H., Ho C-C., Tu Y-C., Tsai H-C., Wang C-A., Su W-F.: High refractive index transparent nanocomposites prepared by in situ polymerization. Journal of Materials Chemistry C, 2, 2251-2258 (2014). https://doi.org/10.1039/C3TC32374A
[81] Zhou H., Wang H., Tian X., Zheng K., Wu Z., Ding X., Ye X.: Preparation of UV-curable transparent poly(urethane acrylate) nanocomposites with excellent UV/IR shielding properties. Composites Science and Technology, 94, 105-110 (2014).

https://doi.org/10.1016/j.compscitech.2014.01.022

[82] Landry C. J. T., Coltrain B. K., Wesson J. A., Zumbulyadis N., Lippert J. L.: In situ polymerization of tetraethoxysilane in polymers: Chemical nature of the interactions. Polymer, 33, 1496-1506 (1992). https://doi.org/10.1016/0032-3861(92)90127-I

[83] Asunskis D. J., Bolotin I. L., Hanley L.: Nonlinear optical properties of $\mathrm{PbS}$ nanocrystals grown in polymer solutions. The Journal of Physical Chemistry C, 112, 9555-9558 (2008).

https://doi.org/10.1021/jp8037076

[84] Bokobza L., Diop A.: Reinforcement of poly(dimethylsiloxane) by sol-gel in situ generated silica and titania particles. Express Polymer Letters, 4, 355-363 (2010). https://doi.org/10.3144/expresspolymlett.2010.45

[85] Chujo Y.: Organic-inorganic nano-hybrid materials. KONA Powder and Particle Journal, 25, 255-260 (2007).

https://doi.org/10.14356/kona.2007023

[86] Ogoshi T., Chujo Y.: Organic-inorganic polymer hybrids prepared by the sol-gel method. Composite Interfaces, 11, 539-566 (2005) https://doi.org/10.1163/1568554053148735

[87] Coltrain B. K., Ferrar W. T., Landry C. J. T., Molaire T. R., Zumbulyadis N.: Polyphosphazene molecular composites. 1. In situ polymerization of tetraethoxysilane. Chemistry of Materials, 4, 358-364 (1992). https://doi.org/10.1021/cm00020a024

[88] Du T., Song H., Ilegbusi O. J.: Sol-gel derived $\mathrm{ZnO/}$ PVP nanocomposite thin film for superoxide radical sensor. Materials Science and Engineering: C, 27, 414 420 (2007). https://doi.org/10.1016/j.msec.2006.05.040

[89] Ellsworth M. W., Novak B. M.: Mutually interpenetrating inorganic-organic networks. New routes into nonshrinking sol-gel composite materials. Journal of the American Chemical Society, 113, 2756-2758 (1991). https://doi.org/10.1021/ja00007a062

[90] Rifai S., Breen C., Solis D. J., Swager T. M.: Facile in situ silver nanoparticle formation in insulating porous polymer matrices. Chemistry of Materials, 18, 21-25 (2006). https://doi.org/10.1021/cm0511419

[91] Hsiue G-H., Chen J-K., Liu Y-L.: Synthesis and characterization of nanocomposite of polyimide-silica hybrid from nonaqueous sol-gel process. Journal of Applied Polymer Science, 76, 1609-1618 (2000). https://doi.org/10.1002/(SICI)10974628(20000613)76:11<1609::AID-APP1>3.0.CO;2-W 
[92] Hsiue G-H., Kuo W-J., Huang Y-P., Jeng R-J.: Microstructural and morphological characteristics of PS$\mathrm{SiO}_{2}$ nanocomposites. Polymer, 41, 2813-2825 (2000). https://doi.org/10.1016/S0032-3861(99)00478-4

[93] $\mathrm{Hu}$ Q., Marand E.: In situ formation of nanosized $\mathrm{TiO}_{2}$ domains within poly(amide-imide) by a sol-gel process. Polymer, 40, 4833-4843 (1999). https://doi.org/10.1016/S0032-3861(98)00264-X

[94] Juangvanich N., Mauritz K. A.: Polyethersulfone-[silicon oxide] hybrid materials via in situ sol-gel reactions for tetra-alkoxysilanes. Journal of Applied Polymer Science, 67, 1799-1810 (1998).

https://doi.org/10.1002/(SICI)10974628(19980307)67:10<1799::AID-APP13>3.0.CO;2-S

[95] Landry C. J., Coltrain B. K., Landry M. R., Fitzgerald J. J., Long V. K.: Poly(vinyl acetate)/silica-filled materials: Material properties of in situ vs fumed silica particles. Macromolecules, 26, 3702-3712 (1993). https://doi.org/10.1021/ma00066a032

[96] Hood M. A., Mari M., Muñoz-Espí R.: Synthetic strategies in the preparation of polymer/inorganic hybrid nanoparticles. Materials, 7, 4057-4087 (2014). hhttps://doi.org/10.3390/ma7054057

[97] Nakane K., Yamashita T., Iwakura K., Suzuki F.: Properties and structure of poly(vinyl alcohol)/silica composites. Journal of Applied Polymer Science, 74, 133 138 (1999).

https://doi.org/10.1002/(SICI)10974628(19991003)74:1<133::AID-APP16>3.0.CO;2-N

[98] Nunes S. P., Peinemann K. V., Ohlrogge K., Alpers A., Keller M., Pires A. T. N.: Membranes of poly(ether imide) and nanodispersed silica. Journal of Membrane Science, 157, 219-226 (1999). https://doi.org/10.1016/S0376-7388(98)00379-2

[99] Onwudiwe D. C., Krüger T. P. J., Oluwatobi O. S., Strydom C. A.: Nanosecond laser irradiation synthesis of CdS nanoparticles in a PVA system. Applied Surface Science, 290, 18-26 (2014).

https://doi.org/10.1016/j.apsusc.2013.10.165

[100] Porel S., Venkatram N., Narayana Rao D., Radhakrishnan T.: In situ synthesis of metal nanoparticles in polymer matrix and their optical limiting applications. Journal of Nanoscience and Nanotechnology, 7, 1887 1892 (2007). https://doi.org/10.1166/jnn.2007.736

[101] Sajimol A. M., Anand P. B., Anilkumar K. M., Jayalekshmi S.: Exceptionally good, transparent and flexible $\mathrm{FeS}_{2} /$ poly(vinyl pyrrolidone) and $\mathrm{FeS}_{2} /$ poly(vinyl alcohol) nanocomposite thin films with excellent UVshielding properties. Polymer International, 62, 670 675 (2013). https://doi.org/10.1002/pi.4348

[102] Kyprianidou-Leodidou T., Margraf P., Caseri W., Suter U. W., Walther P.: Polymer sheets with a thin nanocomposite layer acting as a UV filter. Polymers for Advanced Technologies, 8, 505-512 (1997).

https://doi.org/10.1002/(SICI)10991581(199708)8:8<505::AID-PAT678>3.0.CO;2-U
[103] Sengupta R., Bandyopadhyay A., Sabharwal S., Chaki T. K., Bhowmick A. K.: Polyamide-6,6/in situ silica hybrid nanocomposites by sol-gel technique: Synthesis, characterization and properties. Polymer, 46, 33433354 (2005).

https://doi.org/10.1016/j.polymer.2005.02.104

[104] Silveira K. F., Yoshida I. V. P., Nunes S. P.: Phase separation in PMMA/silica sol-gel systems. Polymer, 36, 1425-1434 (1995).

https://doi.org/10.1016/0032-3861(95)95921-M

[105] Suzuki F., Onozato K., Kurokawa Y.: A formation of compatible poly(vinyl alcohol)/alumina gel composite and its properties. Journal of Applied Polymer Science, 39, 371-381 (1990). https://doi.org/10.1002/app.1990.070390214

[106] Tamaki R., Chujo Y.: Synthesis of poly(vinyl alcohol)/silica gel polymer hybrids by in-situ hydrolysis method. Applied Organometallic Chemistry, 12, 755762 (1998).

https://doi.org/10.1002/(SICI)1099-

0739(199810/11)12:10/11<755::AID-AOC783>3.0.CO;2-A

[107] Tamaki R., Chujo Y.: Synthesis of chitosan/silica gel polymer hybrids. Composite Interfaces, 6, 259-272 (1998).

https://doi.org/10.1163/156855499X00080

[108] Tamaki R., Chujo Y.: Synthesis of polystyrene and silica gel polymer hybrids utilizing ionic interactions. Chemistry of Materials, 11, 1719-1726 (1999). https://doi.org/10.1021/cm9810741

[109] Tamaki R., Samura K., Chujo Y.: Synthesis of polystyrene and silica gel polymer hybrids via $\pi-\pi$ interactions. Chemical Communications, 1998, 1131-1132 (1998). https://doi.org/10.1039/A708948A

[110] Wang S., Wang M., Lei Y., Zhang L.: 'Anchor effect' in poly(styrene maleic anhydride) $/ \mathrm{TiO}_{2}$ nanocomposites. Journal of Materials Science Letters, 18, 2009 2012 (1999). https://doi.org/10.1023/A:1006646219253

[111] Wei Y., Wang W., Yeh J-M., Wang B., Yang D., Murray J. K., Jin D., Wei G.: Vinyl-polymer-modified hybrid materials and photoacid-catalyzed sol-gel reactions. in 'Hybrid organic-inorganic composites' (eds.: Mark J. E., Lee C. Y-C., Bianconi P. A.) ACS Publications, Washington, 125-141 (1995). https://doi.org/10.1021/bk-1995-0585.ch011

[112] Wei Y., Yang D., Tang L., Hutchins M. K.: Synthesis, characterization, and properties of new polystyrene$\mathrm{SiO}_{2}$ hybrid sol-gel materials. Journal of Materials Research, 8, 1143-1152 (1993). https://doi.org/10.1557/JMR.1993.1143

[113] Ziolo R. F., Giannelis E. P., Weinstein B. A., O'Horo M. P., Ganguly B. N., Mehrotra V., Russell M. W., Huffman D. R.: Matrix-mediated synthesis of nanocrystalline $\gamma-\mathrm{Fe}_{2} \mathrm{O}_{3}$ : A new optically transparent magnetic material. Science, 257, 219-223 (1992). https://doi.org/10.1126/science.257.5067.219 
[114] Hajji P., David L., Gerard J. F., Pascault J. P., Vigier G.: Synthesis, structure, and morphology of polymer-silica hybrid nanocomposites based on hydroxyethyl methacrylate. Journal of Polymer Science Part B: Polymer Physics, 37, 3172-3187 (1999).

https://doi.org/10.1002/(SICI)10990488(19991115)37:22<3172::AID-POLB2>3.0.CO;2-R

[115] Novak B. M., Davies C.: 'Inverse' organic-inorganic composite materials. 2. Free-radical routes into nonshrinking sol-gel composites. Macromolecules, 24, 5481-5483 (1991). https://doi.org/10.1021/ma00019a044

[116] Wang S., Ahmad Z., Mark J.: A polyamide-silica composite prepared by the sol-gel process. Polymer Bulletin, 31, 323-330 (1993).

https://doi.org/10.1007/BF00692959

[117] Avadhani C., Chujo Y.: Polyimide-silica gel hybrids containing metal salts: Preparation via the sol-gel reaction. Applied Organometallic Chemistry, 11, 153161 (1997).

https://doi.org/10.1002/(SICI)10990739(199702)11:2<153::AID-AOC563>3.0.CO;2-W

[118] Matějka L., Dušek K., Pleštil J., Kř́ž J., Lednický F.: Formation and structure of the epoxy-silica hybrids. Polymer, 40, 171-181 (1999). https://doi.org/10.1016/S0032-3861(98)00214-6

[119] Wei Y., Wang W., Yeh J-M., Wang B., Yang D., Murray J. K.: Photochemical synthesis of polyacrylate-silica hybrid sol-gel materials catalyzed by photoacids. Advanced Materials, 6, 372-374 (1994).

https://doi.org/10.1002/adma.19940060505

[120] Yuwono A. H., Zhang Y., Wang J.: Investigating the nanostructural evolution of $\mathrm{TiO}_{2}$ nanoparticles in the sol-gel derived $\mathrm{TiO}_{2}$-poly(methyl methacrylate) nanocomposites. International Journal of Technology, 1, 11-19 (2010).

https://doi.org/10.14716/ijtech.v1i1.996

[121] Palkovits R., Althues H., Rumplecker A., Tesche B., Dreier A., Holle U., Fink G., Cheng C., Shantz D., Kaskel S.: Polymerization of w/o microemulsions for the preparation of transparent $\mathrm{SiO}_{2} / \mathrm{PMMA}$ nanocomposites. Langmuir, 21, 6048-6053 (2005). https://doi.org/10.1021/la050630k

[122] Balan L., Burget D.: Synthesis of metal/polymer nanocomposite by UV-radiation curing. European Polymer Journal, 42, 3180-3189 (2006).

https://doi.org/10.1016/j.eurpolymj.2006.08.016

[123] Nakao Y.: Preparation and characterisation of noble metal solid sols in poly(methyl methacrylate). Journal of the Chemical Society, Chemical Communications, 1993, 826-828 (1993).

https://doi.org/10.1039/C39930000826

[124] Pavel F. M., Mackay R. A.: Reverse micellar synthesis of a nanoparticle/polymer composite. Langmuir, 16, 8568-8574 (2000). https://doi.org/10.1021/la000045d
[125] Akhavan A., Sheykh N., Beteshobabrud R.: Polymethylmethacrylate/silver nanocomposite prepared by $\gamma$-ray. Journal of Nuclear Science and Technology, 41, 80-84 (2010).

[126] ASTM D1746, Standard test method for transparency of plastic sheeting (2015).

[127] Bombalski L., Dong H., Listak J., Matyjaszewsk K., Bockstaller M. R.: Null-scattering hybrid particles using controlled radical polymerization. Advanced Materials, 19, 4486-4490 (2007).

https://doi.org/10.1002/adma.200700928

[128] Chevigny C., Dalmas F., Di Cola E., Gigmes D., Bertin D., Boué F., Jestin J.: Polymer-grafted-nanoparticles nanocomposites: Dispersion, grafted chain conformation, and rheological behavior. Macromolecules, 44, 122-133 (2010). https://doi.org/10.1021/ma101332s

[129] Krell A., Hutzler T., Klimke J.: Transmission physics and consequences for materials selection, manufacturing, and applications. Journal of the European Ceramic Society, 29, 207-221 (2009). https://doi.org/10.1016/j.jeurceramsoc.2008.03.025

[130] Natarajan B., Neely T., Rungta A., Benicewicz B. C., Schadler L. S.: Thermomechanical properties of bimodal brush modified nanoparticle composites. Macromolecules, 46, 4909-4918 (2013).

https://doi.org/10.1021/ma400553c

[131] Rungta A., Natarajan B., Neely T., Dukes D., Schadler L. S., Benicewicz B. C.: Grafting bimodal polymer brushes on nanoparticles using controlled radical polymerization. Macromolecules, 45, 9303-9311 (2012). https://doi.org/10.1021/ma3018876

[132] Sunday D., Ilavsky J., Green D. L.: A phase diagram for polymer-grafted nanoparticles in homopolymer matrices. Macromolecules, 45, 4007-4011 (2012). https://doi.org/10.1021/ma300438g

[133] Balta Calleja F., Fakirov S.: Microhardness of polymers. Cambridge University Press, Cambridge (2007).

[134] Verbeek C. J. R.: The influence of interfacial adhesion, particle size and size distribution on the predicted mechanical properties of particulate thermoplastic composites. Materials Letters, 57, 1919-1924 (2003). https://doi.org/10.1016/S0167-577X(02)01105-9

[135] Verbeek C. J. R., Focke W. W.: Modelling the Young's modulus of platelet reinforced thermoplastic sheet composites. Composites Part A: Applied Science and Manufacturing, 33, 1697-1704 (2002).

https://doi.org/10.1016/S1359-835X(02)00184-7

[136] Kausch H-H.: Polymer fracture. Springer, Heidelberg (1987).

[137] Yan W., Lin R. J. T., Bhattacharyya D.: Particulate reinforced rotationally moulded polyethylene composites - Mixing methods and mechanical properties. Composites Science and Technology, 66, 2080-2088 (2006). https://doi.org/10.1016/j.compscitech.2005.12.022 
[138] Saliwal G. R., Pegel S., Göldel A., Pötschke P., Heinrich G.: Analysis of agglomerate dispersion mechanisms of multiwalled carbon nanotubes during melt mixing in polycarbonate. Polymer, 51, 2708-2720 (2010). https://doi.org/10.1016/j.polymer.2010.02.048

[139] Fu S-Y., Chen Z-K., Hong S., Han C. C.: The reduction of carbon nanotube (CNT) length during the manufacture of CNT/polymer composites and a method to simultaneously determine the resulting CNT and interfacial strengths. Carbon, 47, 3192-3200 (2009). https://doi.org/10.1016/j.carbon.2009.07.028

[140] Manchado M. A. L., Valentini L., Biagiotti J., Kenny J. M.: Thermal and mechanical properties of singlewalled carbon nanotubes-polypropylene composites prepared by melt processing. Carbon, 43, 1499-1505 (2005).

https://doi.org/10.1016/j.carbon.2005.01.031

[141] Celzard A., McRae E., Deleuze C., Dufort M., Furdin G., Marêché J. F.: Critical concentration in percolating systems containing a high-aspect-ratio filler. Journal of Physical Review B, 53, 6209-6214 (1996).

https://doi.org/10.1103/PhysRevB.53.6209

[142] Wu L., Glebe U., Böker A.: Surface-initiated controlled radical polymerizations from silica nanoparticles, gold nanocrystals, and bionanoparticles. Polymer Chemistry, 6, 5143-5184 (2015).

https://doi.org/10.1039/C5PY00525F

[143] Müller H., Leube W., Tauer K., Förster S., Antonietti M.: Polyelectrolyte block copolymers as effective stabilizers in emulsion polymerization. Macromolecules, 30, 2288-2293 (1997).

https://doi.org/10.1021/ma9615516

[144] Fakirov S.: Polymer solutions. in 'Fundamentals of polymer science for engineers' (ed.: Fakirov S.:) Wiley, Weinheim, 157-166 (2017).

https://doi.org/10.1002/9783527802180.ch6

[145] Xu W., Ge M., He P.: Nonisothermal crystallization kinetics of polypropylene/montmorillonite nanocomposites. Journal of Polymer Science Part B: Polymer Physics, 40, 408-414 (2002).

https://doi.org/10.1002/polb.10101

[146] Zhao Q., Wang W., Zhang C., Du Z., Mi J.: Understanding the microstructure of particle dispersion in confined copolymer nanocomposites. Physical Chemistry Chemical Physics, 17, 26338-26345 (2015). https://doi.org/10.1039/C5CP03915K

[147] Fan J-B., Song Y., Liu H., Lu Z., Zhang F., Liu H., Meng J., Gu L., Wang S., Jiang L.: A general strategy to synthesize chemically and topologically anisotropic Janus particles. Science Advances, 3, e1603203/1e1603203/9 (2017). https://doi.org/10.1126/sciadv.1603203

[148] Chern C-S.: Principles and applications of emulsion polymerization. Wiley, New York (2008).

[149] Kim J-W., Larsen R. J., Weitz D. A.: Uniform nonspherical colloidal particles with tunable shapes. Advanced Materials, 19, 2005-2009 (2007).

https://doi.org/10.1002/adma.200602345
[150] Matyjaszewski K., Spanswick J.: Atom transfer radical polymerization (ATRP). in 'Reference module in materials science and materials engineering' (ed.: Hashmi S.) Elsevier, Oxford 1-76 (2016). https://doi.org/10.1016/B978-0-12-803581-8.01354-0

[151] Ata M. S., Liu Y., Zhitomirsky I.: A review of new methods of surface chemical modification, dispersion and electrophoretic deposition of metal oxide particles. RSC Advances, 4, 22716-22732 (2014). https://doi.org/10.1039/C4RA02218A

[152] Zoppe J. O., Ataman N. C., Mocny P., Wang J., Moraes J., Klok H-A.: Surface-initiated controlled radical polymerization: State-of-the-art, opportunities, and challenges in surface and interface engineering with polymer brushes. Chemical Reviews, 117, 1105-1318 (2017). https://doi.org/10.1021/acs.chemrev.6b00314

[153] Dang A., Ojha S., Hui C. M., Mahoney C., Matyjaszewski K., Bockstaller M. R.: High-transparency polymer nanocomposites enabled by polymergraft modification of particle fillers. Langmuir, 30, 14434-14442 (2014).

https://doi.org/10.1021/1a5037037

[154] Bockstaller M. R., Mickiewicz R. A., Thomas E. L.: Block copolymer nanocomposites: Perspectives for tailored functional materials. Advanced Materials, 17, 1331-1349 (2005). https://doi.org/10.1002/adma.200500167

[155] Caseri W. R.: Nanocomposites of polymers and inorganic particles: Preparation, structure and properties. Materials Science and Technology, 22, 807-817 (2006). https://doi.org/10.1179/174328406X101256

[156] Sanchez C., Julián B., Belleville P., Popall M.: Applications of hybrid organic-inorganic nanocomposites. Journal of Materials Chemistry, 15, 3559-3592 (2005). https://doi.org/10.1039/B509097K

[157] Vaia R. A., Maguire J. F.: Polymer nanocomposites with prescribed morphology: Going beyond nanoparticle-filled polymers. Chemistry of Materials, 19, 27362751 (2007). https://doi.org/10.1021/cm062693+

[158] Winey K. I., Vaia R. A.: Polymer nanocomposites. MRS Bulletin, 32, 314-322 (2007). https://doi.org/10.1557/mrs2007.229

[159] Althues H., Henle J., Kaskel S.: Functional inorganic nanofillers for transparent polymers. Chemical Society Reviews, 36, 1454-1465 (2007). https://doi.org/10.1039/B608177K

[160] Ehlert S., Stegelmeier C., Pirner D., Förster S.: A general route to optically transparent highly filled polymer nanocomposites. Macromolecules, 48, 5323-5327 (2015).

https://doi.org/10.1021/acs.macromol.5b00565

[161] Zhang Z., Demir K. G., Gu G. X.: Developments in 4D-printing: A review on current smart materials, technologies, and applications. International Journal of Smart and Nano Materials, 10, 205-224 (2019). https://doi.org/10.1080/19475411.2019.1591541 
[162] Formhals A.: Process and apparatus for preparing artificial threads. U.S. Patent 1975504A USA (1934).

[163] Huang Z-M., Zhang Y-Z., Kotaki M., Ramakrishna S.: A review on polymer nanofibers by electrospinning and their applications in nanocomposites. Composites Science and Technology, 63, 2223-2253 (2003). https://doi.org/10.1016/S0266-3538(03)00178-7

[164] Agarwal S., Wendorff J. H., Greiner A.: Use of electrospinning technique for biomedical applications. Polymer, 49, 5603-5621 (2008).

https://doi.org/10.1016/j.polymer.2008.09.014

[165] Lin D. Y., Martin D. C.: Orientation development in electrospun liquid-crystalline polymer nanofibers. in 'Polymeric nanofibers' (eds.: Reneker D. H., Fong H.), ACS Publications, New York, 330-342 (2003). https://doi.org/10.1021/bk-2006-0918.ch023

[166] Mohammadzadehmoghadam S., Dong Y., Barbhuiya S., Guo L., Liu D., Umer R., Qi X., Tang Y.: Electrospinning: Current status and future trends. in 'Nano-size polymers' (ed.: Fakirov S.) Springer, Switzerland, 89154 (2016).

https://doi.org/10.1007/978-3-319-39715-3 4

[167] Papkov D., Pellerin C., Dzenis Y. A.: Polarized Raman analysis of polymer chain orientation in ultrafine individual nanofibers with variable low crystallinity. Macromolecules, 51, 8746-8751 (2018).

https://doi.org/10.1021/acs.macromol.8b01869

[168] Richard-Lacroix M., Pellerin C.: Molecular orientation in electrospun fibers: From mats to single fibers. Macromolecules, 46, 9473-9493 (2013).

https://doi.org/10.1021/ma401681m

[169] Yao J., Bastiaansen C. W. M., Peijs T.: High strength and high modulus electrospun nanofibers. Fibers, 2, 158-186 (2014). https://doi.org/10.3390/fib2020158

[170] Mohan S. D., Mitchell G. R., Davis F. J.: Chain extension in electrospun polystyrene fibres: A SANS study. Soft Matter, 7, 4397-4404 (2011). https://doi.org/10.1039/C0SM01442G

[171] Carrizales C., Pelfrey S., Rincon R., Eubanks T. M., Kuang A., McClure M. J., Bowlin G. L., Macossay J.: Thermal and mechanical properties of electrospun PMMA, PVC, Nylon 6, and Nylon 6,6. Polymers for Advanced Technologies, 19, 124-130 (2008). https://doi.org/10.1002/pat.981

[172] Bazbouz M. B., Stylios G. K.: The tensile properties of electrospun Nylon 6 single nanofibers. Journal of Polymer Science Part B: Polymer Physics, 48, 1719 1731 (2010).

https://doi.org/10.1002/polb.21993

[173] Zussman E., Burman M., Yarin A. L., Khalfin R., Cohen Y.: Tensile deformation of electrospun nylon-6,6 nanofibers. Journal of Polymer Science Part B: Polymer Physics, 44, 1482-1489 (2006).

https://doi.org/10.1002/polb.20803
[174] Sanatgar R. H., Borhani S., Ravandi S. A. H., Gharehaghaji A. A.: The influence of solvent type and polymer concentration on the physical properties of solid state polymerized PA66 nanofiber yarn. Journal of Applied Polymer Science, 126, 1112-1120 (2012). https://doi.org/10.1002/app.36871

[175] Hang F., Lu D., Bailey R. J., Jimenez-Palomar I., Stachewicz U., Cortes-Ballesteros B., Davies M., Zech M., Bödefeld C., Barber A. H.: In situ tensile testing of nanofibers by combining atomic force microscopy and scanning electron microscopy. Nanotechnology, 22, 365708/1-365708/8 (2011).

https://doi.org/10.1088/0957-4484/22/36/365708

[176] Stachewicz U., Peker I., Tu W., Barber A. H.: Stress delocalization in crack tolerant electrospun nanofiber networks. ACS Applied Materials and Interfaces, 3, 1991-1996 (2011). https://doi.org/10.1021/am2002444

[177] Veleirinho B., Rei M. F., Lopes-da-Silva J.: Solvent and concentration effects on the properties of electrospun poly(ethylene terephthalate) nanofiber mats. Journal of Polymer Science Part B: Polymer Physics, 46, 460-471 (2008). https://doi.org/10.1002/polb.21380

[178] Cook J. G.: Handbook of textile fibres: Man-made fibres. Elsevier, Amsterdam (1984).

[179] Ajji A., Coates P. D., Dumoulin M. M., Ward I. M.: Solid phase processing of polymers. Hanser, Munich (2000).

[180] Fakirov S.: Are the electrospun polymers polymeric fibers? Advanced Materials Letters, 20011456/120011456/3 (2020). https://doi.org/10.5185/amlett.2020.011456

[181] Evstatiev M., Fakirov S., Bechtold G., Friedrich K.: Structure-property relationships of injection- and compression-molded microfibrillar-reinforced PET/PA-6 composites. Advances in Polymer Technology, 19, 249 259 (2000).

https://doi.org/10.1002/1098-2329(200024)19:4<249::AIDADV2>3.0.CO;2-R

[182] Evstatiev M., Fakirov S., Krasteva B., Friedrich K., Covas J., Cunha A.: Recycling of poly(ethylene terephthalate) as polymer-polymer composites. Polymer Engineering and Science, 42, 826-835 (2002). https://doi.org/10.1002/pen.10994

[183] Fakirov S.: In situ nano- and microfibrillar polymerpolymer composites. in 'Synthetic polymer-polymer composites' (eds.: Bhattacharyya D., Fakirov S.) Hanser, Munich, 353-400 (2012). https://doi.org/10.3139/9781569905258.011

[184] Fakirov S.: Nano-/microfibrillar polymer-polymer and single polymer composites: The converting instead of adding concept. Composites Science and Technology, 89, 211-225 (2013). https://doi.org/10.1016/j.compscitech.2013.10.007 
[185] Fakirov S., Bhattacharyya D., Lin R. J. T., Fuchs C., Friedrich K.: Contribution of coalescence to microfibril formation in polymer blends during cold drawing. Journal of Macromolecular Science Part B: Physics, 46, 183-194 (2007). https://doi.org/10.1080/00222340601044375

[186] Fakirov S., Bhattacharyya D., Panamoottil S. M.: Converting of bulk polymers into nanosized materials with controlled nanomorphology. International Journal of Polymeric Materials and Polymeric Biomaterials, 63, 777-793 (2014). https://doi.org/10.1080/00914037.2014.886214

[187] Fakirov S., Bhattacharyya D., Shields R. J.: Nanofibril reinforced composites from polymer blends. Colloids and Surfaces A: Physicochemical and Engineering Aspects, 313, 2-8 (2008).

https://doi.org/10.1016/j.colsurfa.2007.05.038

[188] Duhovic M., Bhattacharyya D., Fakirov S.: Nanofibrillar single polymer composites of poly(ethylene terephthalate). Macromolecular Materials and Engineering, 295, 95-99 (2010).

https://doi.org/10.1002/mame.200900237

[189] Kim N. K., Fakirov S., Bhattacharyya D.: Polymerpolymer and single polymer composites involving nanofibrillar poly(vinylidene fluoride): Manufacturing and mechanical properties. Journal of Macromolecular Science Physics B, 53, 1168-1181 (2014). https://doi.org/10.1080/00222348.2014.895632

[190] McCardle R., Bhattacharyya D., Fakirov S.: Effect of reinforcement orientation on the mechanical properties of microfibrillar PP/PET and PET single-polymer composites. Macromolecular Materials and Engineering, 297, 711-723 (2012).

https://doi.org/10.1002/mame.201100220

[191] Panamoottil S. M., Bhattacharyya D., Fakirov S.: Nanofibrillar polymer-polymer and single polymer composite involving poly(butylene terephthalate): Preparation and mechanical properties. Polymer-Plastics Technology and Engineering, 52, 1106-1112 (2013)

https://doi.org/10.1080/03602559.2013.769583

[192] Fakirov S.: Fundamentals of polymer science for engineers. Wiley, Weinheim (2017).

[193] Chen Y. H., Zhong G. J., Li Z. M.: Microfibril reinforced polymer-polymer composites via hot stretching: Preparation, structure and properties. in 'Synthetic polymer-polymer composites' (eds.: Fakirov S., Bhattacharyya D.) Hanser, Munich, 401-436 (2012). https://doi.org/10.3139/9781569905258.012

[194] Li Z-M., Huang C-G., Yang W., Yang M-B., Huang R.: Morphology dependent double yielding in injection molded polycarbonate/polyethylene blend. Macromolecular Materials and Engineering, 289, 1004-1011 (2004).

https://doi.org/10.1002/mame.200400145
[195] Li Z-M., Li L-B., Shen K-Z., Yang M-B., Huang R.: In-situ microfibrillar PET/iPP blend via slit die extrusion, hot stretching, and quenching: Influence of hot stretch ratio on morphology, crystallization, and crystal structure of iPP at a fixed PET concentration. Journal of Polymer Science Part B: Polymer Physics, 42, 40954106 (2004).

https://doi.org/10.1002/polb.20262

[196] Li Z-M., Yang M-B., Lu A., Feng J-M., Huang R.: Tensile properties of poly(ethylene terephthalate) and polyethylene in-situ microfiber reinforced composite formed via slit die extrusion and hot-stretching. Materials Letters, 56, 756-762 (2002).

https://doi.org/10.1016/S0167-577X(02)00609-2

[197] Li Z-M., Yang M-B., Xie B-H., Feng J-M., Huang R.: In-situ microfiber reinforced composite based on PET and PE via slit die extrusion and hot stretching: Influences of hot stretching ratio on morphology and tensile properties at a fixed composition. Polymer Engineering and Science, 43, 615-628 (2003). https://doi.org/10.1002/pen.10050

[198] Li Z-M., Lu A., Lu Z-Y., Shen K-Z., Li L-B., Yang M-B.: In-situ microfibrillar PET/iPP blend via a slit die extrusion, hot stretching and quenching process: Influences of PET concentration on morphology and crystallization of iPP at a fixed hot stretching ratio. Journal of Macromolecular Science Part B: Physics, 44203 216 (2005)

https://doi.org/10.1081/MB-200049793

[199] Zhong G-J., Li L., Mendes E., Byelov D., Fu Q., Li Z-M.: Suppression of skin-core structure in injectionmolded polymer parts by in situ incorporation of a microfibrillar network. Macromolecules, 39, 6771-6775 (2006). https://doi.org/10.1021/ma0604845

[200] Zhong G-J., Li Z-M., Li L., Shen K.: Crystallization of oriented isotactic polypropylene (iPP) in the presence of in situ poly(ethylene terephthalate) (PET) microfibrils. Polymer, 49, 4271-4278 (2008). https://doi.org/10.1016/j.polymer.2008.07.056

[201] Yi X., Xu L., Wang Y-L., Zhong G-J., Ji X., Li Z-M.: Morphology and properties of isotactic polypropylene/poly(ethylene terephthalate) in situ microfibrillar reinforced blends: Influence of viscosity ratio. European Polymer Journal, 46, 719-730 (2010). https://doi.org/10.1016/j.eurpolymj.2009.12.027

[202] Fakirov S.: From polymer blends to nano-size materials with controlled nanomorphology. in 'Nano-size polymers' (ed.: Fakirov S.) Springer, Cham, 179-200 (2016). https://doi.org/10.1007/978-3-319-39715-3_6

[203] Fakirov S.: Nano-size polymers: Preparation, properties, applications. Springer, New York (2016). 
[204] Lin S. T. C., Bhattacharyya D., Fakirov S., Cornish J.: Novel organic solvent free micro-/nano-fibrillar, nanoporous scaffolds for tissue engineering. International Journal of Polymeric Materials and Polymeric Biomaterials, 63, 416-423 (2014). https://doi.org/10.1080/00914037.2013.854210

[205] Lin S., Bhattacharyya D., Fakirov S., Matthews B., Cornish J.: A novel microfibrillar composite approach towards manufacturing nanoporous tissue scaffolds. Mechanics of Advanced Materials and Structures, 21, 237-243 (2014). https://doi.org/10.1080/15376494.2013.834098

[206] Fakirov S.: Modified Soxhlet apparatus for high-temperature extraction. Journal of Applied Polymer Science, 102, 2013-2014 (2006).

https://doi.org/10.1002/app.23397

[207] Hine P. J., Ward I. M.: Hot compaction of woven poly (ethylene terephthalate) multifilaments. Journal of Applied Polymer Science, 91, 2223-2233 (2004). https://doi.org/10.1002/app.13343

[208] Alishiri M., Shojaei A., Abdekhodaie M. J.: Biodegradable polyurethane acrylate/hema-grafted nanodiamond composites with bone regenerative potential applications: Structure, mechanical properties and biocompatibility. RSC Advances, 6, 8743-8755 (2016).

https://doi.org/10.1039/C5RA19669H

[209] Fakirov S.: Nano- and microfibrillar single-polymer composites: A review. Macromolecular Materials and Engineering, 298, 9-32 (2013).

https://doi.org/10.1002/mame.201200226

[210] Gao C., Yu L., Liu H., Chen L.: Development of selfreinforced polymer composites. Progress in Polymer Science, 37, 767-780 (2012).

https://doi.org/10.1016/j.progpolymsci.2011.09.005

[211] Hine P. J., Ward I. M., Abo El Maaty M. I., Olley R. H., Bassett D. C.: The hot compaction of 2-dimensional woven melt spun high modulus polyethylene fibres. Journal of Materials Science, 35, 5091-5099 (2000). https://doi.org/10.1023/A:1004835816735

[212] Hine P., Broome V., Ward I.: The incorporation of carbon nanofibres to enhance the properties of self reinforced, single polymer composites. Polymer, 46, 10936 10944 (2005).

https://doi.org/10.1016/j.polymer.2005.08.076

[213] Karger-Kocsis J., Fakirov S.: Polymorphism- and stereoregularity-based single polymer composites. in 'Synthetic polymer-polymer composites' (eds.: Bhattacharyya D., Fakirov S.), Elsevier, Amsterdam, 673698 (2012).

https://doi.org/10.3139/9781569905258.020
[214] Kmetty Á., Bárány T., Karger-Kocsis J.: Self-reinforced polymeric materials: A review. Progress in Polymer Science, 35, 1288-1310 (2010). https://doi.org/10.1016/j.progpolymsci.2010.07.002

[215] Matabola K., de Vries A., Moolman F., Luyt A.: Single polymer composites: A review. Journal of Materials Science, 44, 6213-6222 (2009).

https://doi.org/10.1007/s10853-009-3792-1

[216] Haleem Y. A., Liu D., Chen W., Wang C., Hong C., He Z., Liu J., Song P., Yu S., Song L.: Surface functionalization and structure characterizations of nanodiamond and its epoxy based nanocomposites. Composites Part B: Engineering, 78, 480-487 (2015). https://doi.org/10.1016/j.compositesb.2015.04.012

[217] Al-Saleh M. H., Sundararaj U.: Review of the mechanical properties of carbon nanofiber/polymer composites. Composites Part A: Applied Science and Manufacturing, 42, 2126-2142 (2011).

https://doi.org/10.1016/j.compositesa.2011.08.005

[218] Camenzind A., Caseri W. R., Pratsinis S. E.: Flamemade nanoparticles for nanocomposites. Nano Today, 5, 48-65 (2010). https://doi.org/10.1016/j.nantod.2009.12.007

[219] Coleman J. N., Cadek M., Blake R., Nicolosi V., Ryan K. P., Belton C., Fonseca A., Nagy J. B., Gun'ko Y. K., Blau W. J.: High performance nanotube-reinforced plastics: Understanding the mechanism of strength increase. Advanced Functional Materials, 14, 791-798 (2004). https://doi.org/10.1002/adfm.200305200

[220] Ning N., Fu S., Zhang W., Chen F., Wang K., Deng H., Zhang Q., Fu Q.: Realizing the enhancement of interfacial interaction in semicrystalline polymer/filler composites via interfacial crystallization. Progress in Polymer Science, 37, 1425-1455 (2012). https://doi.org/10.1016/j.progpolymsci.2011.12.005

[221] Ji X. L., Jing J. K., Jiang W., Jiang B. Z.: Tensile modulus of polymer nanocomposites. Polymer Engineering and Science, 42, 983-993 (2002).

https://doi.org/10.1002/pen.11007

[222] Bhattacharyya D., Maitrot P., Fakirov S.: Polyamide 6 single polymer composites. Express Polymer Letters, 3, 525-532 (2009). https://doi.org/10.3144/expresspolymlett.2009.65

[223] Shields R. J., Bhattacharyya D., Fakirov S.: Oxygen permeability analysis of microfibril reinforced composites from PE/PET blends. Composites Part A: Applied Science and Manufacturing, 39, 940-949 (2008). https://doi.org/10.1016/j.compositesa.2008.03.008

[224] Fakirov S., Evstatiev M.: New routes to polyethylene terephthalate with improved mechanical properties. Polymer, 31, 431-434 (1990).

https://doi.org/10.1016/0032-3861(90)90380-H 